MATHEMATICS OF COMPUTATION

Volume 67, Number 224, October 1998, Pages 1493-1515

S 0025-5718(98)01005-9

\title{
HIGH ORDER METHODS \\ FOR WEAKLY SINGULAR INTEGRAL EQUATIONS WITH NONSMOOTH INPUT FUNCTIONS
}

\author{
G. MONEGATO AND L. SCUDERI
}

Dedicated to Professor M. R. Occorsio on the occasion of his 65th birthday

\begin{abstract}
To solve one-dimensional linear weakly singular integral equations on bounded intervals, with input functions which may be smooth or not, we propose to introduce first a simple smoothing change of variable, and then to apply classical numerical methods such as product-integration and collocation based on global polynomial approximations. The advantage of this approach is that the order of the methods can be arbitrarily high and that the associated linear systems one has to solve are very well-conditioned.
\end{abstract}

\section{INTRODUCTION}

In this paper we consider classical Fredholm integral equations of the second kind

$$
u(y)-\int_{-1}^{1} k(x, y) u(x) d x=f(y),-1 \leq y \leq 1,
$$

with weakly singular kernels $k(x, y)$; the right-hand side $f$ can be smooth or have irregularities. In particular we examine the case of displacement kernels of the form $k(|x-y|)$, with

$$
k(t) \equiv k_{\alpha}(t):=t^{\alpha}, \alpha>-1 \quad \text { or } \quad k(t) \equiv k_{0}^{\star}(t):=\log (t),
$$

and, more in general, kernels which may be decomposed as

$$
k(x, y)=h_{1}(x-y) \log |x-y|+h_{2}(x-y)|x-y|^{\alpha}+h_{3}(x-y),
$$

with $h_{i}$ smooth and $\alpha>-1$.

For this type of equations the behaviour of their solutions in $[-1,1]$ is known; see, for instance, [6], [17], [19], [20], [25]. When the input function $f$ is smooth, let us say $f \in C^{r+1}[-1,1]$, the solution $u(x)$ has only endpoint mild singularities, that is, $u \in C^{r}(-1,1)$. For example, in the case of (1.1) with $k(x, y)=\log |x-y|$ the solution $u(x)$ admits an expansion containing a finite number of terms of the form (see [19])

$$
(1 \pm x)^{i} \log ^{j}(1 \pm x), \quad i, j=1,2, \ldots, r, \quad i \geq j
$$

Received by the editor July 22, 1996.

1991 Mathematics Subject Classification. Primary 65R20.

This work was supported by the Ministero dell'Universitá e della Ricerca Scientifica e Tecnologica of Italy. 
TABLE 1. Estimated condition numbers.

\begin{tabular}{|c|c|c|c|c|c|}
\hline & $d=2$ & $d=3$ & $d=4$ & $d=5$ & $d=6$ \\
$N$ & $q=2.6$ & $q=3.1$ & $q=3.6$ & $q=4.1$ & $q=4.6$ \\
\hline 4 & $3.6 \mathrm{E}+00$ & $4.4 \mathrm{E}+00$ & $4.9 \mathrm{E}+00$ & $5.3 \mathrm{E}+00$ & $4.6 \mathrm{E}+12$ \\
\hline 8 & $4.0 \mathrm{E}+00$ & $5.0 \mathrm{E}+00$ & $5.7 \mathrm{E}+00$ & $6.4 \mathrm{E}+00$ & $5.2 \mathrm{E}+31$ \\
\hline 16 & $4.6 \mathrm{E}+00$ & $5.3 \mathrm{E}+00$ & $5.9 \mathrm{E}+00$ & $7.0 \mathrm{E}+04$ & $2.4 \mathrm{E}+65$ \\
\hline 32 & $4.8 \mathrm{E}+00$ & $5.3 \mathrm{E}+00$ & $2.7 \mathrm{E}+04$ & $3.1 \mathrm{E}+12$ & \\
\hline 64 & $5.0 \mathrm{E}+00$ & $5.4 \mathrm{E}+00$ & $1.5 \mathrm{E}+09$ & $2.6 \mathrm{E}+19$ & \\
\hline
\end{tabular}

plus a function of class $C^{r}[-1,1]$. If $f$ or one of its first derivatives has, for example, simple jumps at a finite number of points in $(-1,1)$ and is smooth elsewhere, by applying Richter's theory (see [19]), one derives that $u(x)$ may be expressed as a linear combination of $f$ and a finite number of terms which are mildly singular, as those in (1.4), either at \pm 1 or at the jump points of $f$, plus an unknown smooth function.

The knowledge of the behaviour of the solution of (1.1) is crucial if one wants to tune the chosen numerical approach in order to obtain an optimal rate of convergence. Indeed, classical numerical methods such as product-integration, collocation and Galerkin are all constructed on properly graded meshes with piecewise polynomial approximation of the solution. The needed grading parameter for the mesh is related to the behaviour of the solution (see [5], [21], [26]). For example, in the case of (1.1) with $k(x, y)=\log |x-y|$ and $f$ smooth, by using a product-integration method based on piecewise polynomials of degree $d$, with break-points

$$
\begin{array}{ll}
x_{l}=-1+\left(\frac{2 l}{N}\right)^{q}, & 0 \leq l \leq \frac{N}{2}, \\
x_{l}=-x_{N-l}, & \frac{N}{2}<l \leq N,
\end{array}
$$

where $q>1$ characterizes the degree of non-uniformity of the mesh, we can reach an optimal order of convergence $O\left(h^{d+1}\right)$, where $h=\max _{l}\left|x_{l+1}-x_{l}\right|$. Also collocation and Galerkin methods require the same mesh grading to reach the optimal rate of convergence. It is common belief that these methods are the most efficient numerical approaches for the solution of (1.1); by taking the local polynomial degree $d$ arbitrarily large, we can obtain an order of convergence as high as we like. In practice, using computer arithmetic, this last statement does not appear to be true. Indeed, as the local degree $d$ increases, the concentration of knots near the singular points of $u$ is so high that the final linear system one has to solve becomes rapidly ill-conditioned. Moreover, also their implementation becomes more expensive. In Table 1 we report some values of the (linear system) condition number estimated by a routine from the ABACI Library [27], when the product-integration method described above, with local nodes chosen coinciding with the zeros of the $(d+1)$ degree Legendre polynomial (see [21]), was applied to (1.1) with kernel $k_{0}^{\star}(t)$ and $f(y)=y$.

Notice that the total number of interpolation points in $(-1,1)$ at which it is required that the approximants satisfy equation (1.1) (that is, the order of the linear system we have to solve) is $n=N(d+1)$. These condition numbers, particularly the large ones, appear a little pessimistic; however their growing behaviour has 
been confirmed by the numerical results we have obtained; see, for instance, Table 6.

In the case of the corresponding collocation and Galerkin methods, the condition numbers of the final linear systems appear to have a similar behaviour. Those of the Galerkin method are actually a little larger (see Table 7).

For these reasons, in spite of the theoretical results, one should not choose $d$ greater than, let us say for example, 4. Graded meshes theoretically allow an arbitrarily high order of convergence, but in practice also generate increasingly ill-conditioned linear systems. Thus in practice the superiority of methods using graded mesh over others, such as those we shall mention next, is severely limited from the point of view of the order of convergence.

Although in some cases numerical methods based on global polynomial approximations have been proposed (see [13], [14]), in general they have not been considered competitive for the solution of (1.1) because of their fixed (and generally low) rate of convergence. For example, in the case of (1.1) with smooth right-hand side, the product-integration method with $n$-point product quadrature rule based on the zeros of Legendre polynomials gives the following bounds:

$$
\left\|u-u_{n}\right\|_{\infty}= \begin{cases}O\left(n^{-4} \log ^{2} n\right) & \text { if } k=k_{0}^{\star}, \\ O\left(n^{-4-2 \alpha} \log n\right) & \text { if } k=k_{\alpha} \text { and }-\frac{3}{4}<\alpha<0,\end{cases}
$$

where $u_{n}$ denotes the interpolant defined by the method. However, the linear systems generated by these methods have shown to be very well-conditioned. This is due to the fact that the zeros of Legendre, and more generally those of Jacobi, polynomials have a mildly non-uniform distribution in $(-1,1)$ : the distance between two consecutive ones is of order $O\left(n^{-2}\right)$ near the endpoints \pm 1 , and $O\left(n^{-1}\right)$ in the middle of the interval of integration.

In the next sections we will show that if in (1.1) we preliminarly introduce a very simple nonlinear (smoothing) transformation, we can obtain a new equation whose solution can be as smooth as we like. The subsequent application of a method based on global polynomial approximation will then give an arbitrarily high order of convergence. The nonlinear trasformation of the independent variable will simultaneously absorb all irregularities of $u(x)$ and all those of $f(y)$. It will however introduce a perturbation in the kernel of (1.1), but the new equation will not raise any difficulties for the implementation of the associated numerical method.

In Section 2, we define the above transformation, examine the new form that it will give to (1.1), and derive an expansion for the solution of the transformed equation. In Sections 3 and 4, we consider a product-integration and a collocation method, respectively, prove their stability and derive convergence estimates. Finally, in Section 5, we present several numerical results, showing the efficiency of the new approach.

\section{THE SMOOTHING TRANSFORMATION}

For simplicity we first consider a particular case of kernel (1.3), containing only the logarithmic singularity, namely an equation of the form

$$
u(y)-\int_{-1}^{1} h_{1}(x, y) \log |x-y| u(x) d x-\int_{-1}^{1} h_{3}(x, y) u(x) d x=f(y),-1 \leq y \leq 1,
$$


with displacement kernels $h_{i}(x, y)=h_{i}(x-y)$ smooth (for simplicity, in the following we will always assume $\left.h_{i}(t) \in C^{\infty}([-2,2])\right)$, and an inhomogeneous term $f$ which may have finite jumps or singularities, eventually in one of its derivatives, at a finite number of points of $(-1,1)$. We shall denote these by $-1<y_{1}<y_{2}<\ldots<$ $y_{M}<1$, and assume that $f$ is smooth (for simplicity $C^{\infty}$ ) everywhere in $[-1,1]$, except at the $y_{k}$ 's $(k=1, \ldots, M)$ where its singularities satisfy the conditions

$$
\left|\left(y-y_{k}\right)^{i+1} f^{(i)}(y)\right| \leq c, \quad i=0,1, \ldots,
$$

in a neighbourhood of $y_{k}$. It is well-known that integral equations of type (2.1) in general have solutions $u(x)$ which show (endpoint) singular behaviour in their derivatives even when $f(y)$ is smooth. When $f$ is not smooth, $u(x)$ contains in addition new singularities, which are generated by those of $f$ and satisfy (2.2). Indeed, by applying for example Richter's theory (but see also [6]) to the simpler case $h_{1}(x, y) \equiv 1, M=1, y_{1}=0$, and assuming $f$ a piecewise $C^{\infty}$ function with a simple jump at $y_{1}=0$, we obtain the following expansion for $u(x)$ :

$$
\begin{aligned}
u(x)=f(x)+\sum_{i=1}^{r} \sum_{j=1}^{i} & {\left[a_{i j}(1+x)^{i} \log ^{j}(1+x)+b_{i j} x^{i} \log ^{j}|x|\right.} \\
& \left.+c_{i j}(1-x)^{i} \log ^{j}(1-x)\right]+u_{0}(x),
\end{aligned}
$$

where $a_{i j}, b_{i j}$ and $c_{i j}$ are constants, and $u_{0} \in C^{r}[-1,1]$ with $r$ arbitrarily large. If $f$ has more than one interior jump, then in the expansion of $u(x)$ we have the corresponding $\left(x-y_{k}\right)^{i} \log ^{j}\left|x-y_{k}\right|$ singular terms. Analogous results have also been obtained for the well-known $E_{1}(\sigma|x-y|)$ kernel of the linear transport equation, which admits the following decomposition of type (1.3):

$$
E_{1}(t)=k_{1}(t)+t k_{2}(t)+\log t,
$$

where $k_{1}$ and $k_{2}$ are entire functions (see [14]).

From Richter's theory we can also claim that if the singularities of $f$ satisfy condition (2.2), so do those of $u$. This result suggested to us that, by introducing a simple nonlinear change of variable, we can always regularize both $u(x)$ and $f(y)$, hence transform (2.1) into a corresponding weakly singular integral equation with smooth right-hand side and solution. Once we have carried out the smoothing step, we can apply classical methods based on global approximation and obtain high order rates of convergence.

The idea of smoothing the solution by introducing a suitable nonlinear mapping is not new. It has been proposed for example in [3], [4], [8] and [18], and more recently in [15]. However, in these papers the transformation has been considered to solve particular problems where previous methods were not so successful. Here we propose a general technique which may have a wider applicability. Our work has been strongly inspired by the excellent results obtained in [15].

Taking into account expansion (2.3), we choose a nonlinear transformation $x=$ $\gamma(t)$, where $\gamma(t)$ is a sufficiently smooth monotone function mapping $[-1,1]$ onto $[-1,1]$, having $y_{0}=-1, y_{1}, \ldots, y_{M}, y_{M+1}=1$, as fixed points, i.e. $y_{k}=\gamma\left(y_{k}\right)$, and whose leading derivatives vanish at $\left\{y_{k}\right\}$. The simplest, and most efficient from the computational point of view, among those satisfying the above properties is the piecewise Hermite interpolation polynomial $H_{M}(t)$ associated with the partition $-1 \equiv y_{0}<y_{1}<y_{2}<\ldots<y_{M}<y_{M+1} \equiv 1$ of $[-1,1]$ and defined in each 
subinterval $\left[y_{k}, y_{k+1}\right], k=0, \ldots, M$, by the conditions

$$
\begin{cases}H_{M}\left(y_{j}\right)=y_{j}, & j=k, k+1, \\ H_{M}^{(i)}\left(y_{j}\right)=0, & j=k, k+1, \quad i=1, \ldots, \alpha_{j}-1, \quad \alpha_{j} \geq 2 .\end{cases}
$$

The integers $\alpha_{k}, k=0, \ldots, M+1$, are chosen accordingly to the smoothing effect that $\gamma(t)$ ought to produce at the points $y_{k}, k=0, \ldots, M+1$. Notice that the smoothness of $\gamma(t)$ itself does not depend on the choice of $\alpha_{0}$ and $\alpha_{M+1}$.

The construction and evaluation of $H_{M}(t)$ and $H_{M}^{\prime}(t)$ is not as trivial as it might appear at first, particularly if we want to have an automatic program where the $\left\{\alpha_{k}\right\}$ may be arbitrarily chosen. A numerically stable and efficient procedure is the following one.

Since we know a priori that in $\left[y_{k}, y_{k+1}\right]$

$$
H_{M}^{\prime}(t)=c_{k}\left(t-y_{k}\right)^{\alpha_{k}-1}\left(y_{k+1}-t\right)^{\alpha_{k+1}-1},
$$

where $c_{k}$ is a suitable constant, we can use this expression to derive the following representation for $H_{M}(t)$ :

$$
H_{M}(t)=c_{k} \int_{y_{k}}^{t}\left(x-y_{k}\right)^{\alpha_{k}-1}\left(y_{k+1}-x\right)^{\alpha_{k+1}-1} d x+y_{k}, \quad t \in\left[y_{k}, y_{k+1}\right] .
$$

By imposing the conditions $H_{M}\left(y_{k+1}\right)=y_{k+1}, k=0, \ldots, M$, we determine the coefficients $c_{k}$ as

$$
c_{k}=\left(y_{k+1}-y_{k}\right)^{2-\alpha_{k}-\alpha_{k+1}} \frac{\left(\alpha_{k}+\alpha_{k+1}-1\right) !}{\left(\alpha_{k}-1\right) !\left(\alpha_{k+1}-1\right) !}, k=0, \ldots, M .
$$

Using (2.6), $H_{M}(t)$ can be evaluated exactly (up to machine accuracy), without any loss of precision, by using an $N$-point Gauss-Legendre quadrature rule, with $N=\left\lfloor\frac{\alpha_{k}+\alpha_{k+1}}{2}\right\rfloor{ }^{1}$

We have also used a piecewise rational transformation based on a rational function used in [3]; however, it has the drawback of introducing complex conjugate poles near the interval of integration, which make more difficult the calculation of the integrals required by the numerical method, chosen to solve the assigned integral equation. In any case this transformation did not give results as accurate as those, we have obtained by using our $\gamma(t)=H_{M}(t)$.

Thus, introducing in (2.1) the change of variables $x=\gamma(t)$ and $y=\gamma(s)$, we have

$$
\begin{aligned}
u(\gamma(s)) & -\int_{-1}^{1} h_{1}(\gamma(t), \gamma(s)) \log |\gamma(t)-\gamma(s)| u(\gamma(t)) \gamma^{\prime}(t) d t \\
& -\int_{-1}^{1} h_{3}(\gamma(t), \gamma(s)) u(\gamma(t)) \gamma^{\prime}(t) d t=f(\gamma(s)),-1 \leq s \leq 1 .
\end{aligned}
$$

On multiplying through by $\gamma^{\prime}(s)$, and introducing the new unknown function

$$
\varphi(t)=u(\gamma(t)) \gamma^{\prime}(t), \quad-1 \leq t \leq 1,
$$

\footnotetext{
${ }^{1}\lfloor x\rfloor=$ the greatest integer less than or equal to $x$.
} 
we finally obtain the equation

$$
\begin{aligned}
\varphi(s) & -\int_{-1}^{1} \bar{h}_{1}(t, s) \gamma^{\prime}(s) \log |\gamma(t)-\gamma(s)| \varphi(t) d t \\
& -\int_{-1}^{1} \bar{h}_{3}(t, s) \gamma^{\prime}(s) \varphi(t) d t=g(s),-1 \leq s \leq 1,
\end{aligned}
$$

where we have set $\bar{h}_{i}(t, s)=h_{i}(\gamma(t), \gamma(s))$ and $g(s)=f(\gamma(s)) \gamma^{\prime}(s)$. In the following, equation (2.8) will also be considered in the operator form

$$
\left(I-K^{\gamma}\right) \varphi=g .
$$

From the computational point of view, it is more convenient to set

$$
\delta_{0}^{\star}(t, s)= \begin{cases}\log \left[\frac{\gamma(t)-\gamma(s)}{t-s}\right] & \text { if } t \neq s, \\ \log \left[\gamma^{\prime}(s)\right] & \text { if } t=s \neq y_{k}, k=0, \ldots, M+1,\end{cases}
$$

and hence rewrite $(2.8)$ as follows:

$$
\begin{aligned}
\varphi(s) & -\int_{-1}^{1} \log |t-s| \bar{h}_{1}(t, s) \gamma^{\prime}(s) \varphi(t) d t \\
& -\int_{-1}^{1}\left[\bar{h}_{1}(t, s) \delta_{0}^{\star}(t, s)+\bar{h}_{3}(t, s)\right] \gamma^{\prime}(s) \varphi(t) d t=g(s), \quad-1 \leq s \leq 1,
\end{aligned}
$$

or, equivalently, as

$$
\left(I-K_{1}^{\gamma}-K_{2}^{\gamma}\right) \varphi=g
$$

since otherwise we would not be able to handle numerically our operator with the $\log |\gamma(t)-\gamma(s)|$ kernel.

In the following, by $C^{l, \mu}$ we will denote the space of functions whose $l$-derivatives satisfy a Hölder condition with exponent $\mu, 0<\mu \leq 1$, in their domain of definition (see [9]). We will also consider the space $C^{\mu}:=C^{0, \mu}$.

Notice that essentially the nonlinear change of variables has generated in (2.9) a perturbation kernel of the form

$$
\bar{h}_{1}(t, s) \delta_{0}^{\star}(t, s) \gamma^{\prime}(s)
$$

where the factor $\delta_{0}^{\star}(t, s)$ has only fixed-point singularities at $t=s=y_{k}$; therefore (2.10) can be made arbitrarily smooth because it contains the factor $\gamma^{\prime}(s)$. Its degree of smoothness depends upon the choice of the parameters $\alpha_{k}, k=0, \ldots, M+$ 1, in (2.4). For example, the conditions $\alpha_{k}=l+2, k=0, \ldots, M+1$, guarantee that (2.10) belongs to $C^{l, 1-\varepsilon}\left([-1,1]^{2}\right), \varepsilon$ being a positive arbitrarily small number, and that $\bar{h}_{3}(t, s) \gamma^{\prime}(s), g(s)$ and $\varphi(s)$ belong to $C^{l, 1}$.

The price we have to pay for introducing a transformation $\gamma(t)$ with the above properties is that once we have computed $\varphi(t)$, we cannot recover directly from (2.7) the original solution $u(x)$ at the points $\left\{y_{k}\right\}$, but eventually we need to use some interpolation process; but we think that this drawback is very minor.

The behaviour of the new unknown function $\varphi(t)$ can be derived from the corresponding behaviour of $u(x)$ that we have described in the first part of this section. For example, in the case of (2.3), recalling (2.5) and (2.7), we obtain for $\varphi(t)$ an expansion containing the inhomogeneous term $g$, singular terms of the form

$$
\left(t-y_{k}\right)^{(i+1) \alpha_{k}-1} \log ^{j}\left|t-y_{k}\right|, \quad k=0, \ldots, M+1, i \geq j \geq 1,
$$

plus a smooth function. 
Next, we consider an equation of type (2.1) with an algebraic kernel, that is,

$$
u(y)-\int_{-1}^{1} h_{2}(x, y)|x-y|^{\alpha} u(x) d x-\int_{-1}^{1} h_{3}(x, y) u(x) d x=f(y),-1 \leq y \leq 1,
$$

with $\alpha>-1$ not an integer, and where $h_{i}(x, y)$ and $f(y)$ satisfy the same assumptions as those in (2.1).

Also in this case we can apply Richter's theory. In particular, in the simpler case $h_{2}(x, y) \equiv 1$, with $f$ or one of its derivatives having a simple jump at $y_{k}$, for the solution $u(x)$ we obtain an expansion of type (2.3) containing singular terms of the form (see [19])

$$
\left|x-y_{k}\right|^{i(1+\alpha)+j}, \quad i \geq 1, j \geq 0, i \geq j .
$$

For rational $\alpha$, the exponents $i(1+\alpha)$ will become integers at regular intervals; in such a case the corresponding terms must be replaced by

$$
\left|x-y_{k}\right|^{i(1+\alpha)+j} \log ^{p}\left|x-y_{k}\right|,
$$

where $p$ denotes the $p$-th time an integer exponent occurs.

The introduction of our smoothing transformation leads to the following new form of (2.12):

$$
\begin{aligned}
\varphi(s) & -\int_{-1}^{1} \bar{h}_{2}(t, s) \gamma^{\prime}(s)|\gamma(t)-\gamma(s)|^{\alpha} \varphi(t) d t \\
& -\int_{-1}^{1} \bar{h}_{3}(t, s) \gamma^{\prime}(s) \varphi(t) d t=g(s),-1 \leq s \leq 1,
\end{aligned}
$$

or, equivalently,

$$
\left(I-K^{\gamma}\right) \varphi=g
$$

In this case we prefer to set

$$
\delta_{\alpha}(t, s)= \begin{cases}{\left[\frac{\gamma(t)-\gamma(s)}{t-s}\right]^{\alpha}} & \text { if } t \neq s, \\ {\left[\gamma^{\prime}(s)\right]^{\alpha}} & \text { if } t=s\left(\neq y_{k}, k=0, \ldots, M+1, \text { if } \alpha<0\right),\end{cases}
$$

and rewrite (2.14) as follows:

$$
\begin{aligned}
\varphi(s) & -\int_{-1}^{1}|t-s|^{\alpha} \bar{h}_{2}(t, s) \delta_{\alpha}(t, s) \gamma^{\prime}(s) \varphi(t) d t \\
& -\int_{-1}^{1} \bar{h}_{3}(t, s) \gamma^{\prime}(s) \varphi(t) d t=g(s),-1 \leq s \leq 1,
\end{aligned}
$$

or, equivalently, as

$$
\left(I-K_{1}^{\gamma}-K_{2}^{\gamma}\right) \varphi=g .
$$

Notice that because of the $\gamma^{\prime}(s)$ factor we can make

$$
\bar{h}_{2}(t, s) \delta_{\alpha}(t, s) \gamma^{\prime}(s)
$$

as smooth as we like. For example, the conditions $\alpha_{k}=1+\left[\frac{l}{1+\alpha}\right],{ }^{2} k=0, \ldots, M+1$, guarantee that $(2.16)$ belongs to $C^{l, \mu}\left([-1,1]^{2}\right)$ with $\mu=\left\lceil\frac{l}{1+\alpha}\right\rceil(1+\alpha)-l$.

\footnotetext{
${ }^{2}\lceil x\rceil=$ the smallest integer greater than or equal to $x$.
} 
In the case of (2.12), taking into account the expansion of the corresponding solution $u$ (see (2.13)), for the solution $\varphi(t)$ of (2.15) we obtain an expansion containing $g$, singular terms of the form

$$
\left|t-y_{k}\right|^{[i(1+\alpha)+j+1] \alpha_{k}-1}, \quad i \geq 1, j \geq 0, i \geq j,
$$

plus a smooth function. As for $(2.13)$, if $[i(1+\alpha)+j+1] \alpha_{k}$ becomes an integer we must add a corresponding $\log ^{p}\left|t-y_{k}\right|$ factor.

Before being allowed to take (2.9) or (2.15) as reference equation to which to apply a numerical method, we have to check that the nonlinear transformation has not spoiled it of the uniqueness property that the solution of the corrispondent original equation has. The proof of the following lemma is very similar to that of an analogous result proved in [15].

Lemma 1. If the equation (2.1) ((2.12)) with $f \equiv 0$ has no nontrivial solutions $u \in L^{p}(-1,1)$ for any $p>1,{ }^{3}$ then equation (2.8) ((2.14)) has a unique solution $\varphi \in L^{2}(-1,1)$.

Proof. For brevity, we shall prove the lemma only referring to the equation (2.1), since the same proof holds also for equation (2.12).

We notice first that the operator $K^{\gamma}$ in $\left(2.8^{\prime}\right)$ is compact in $L^{2}(-1,1)$; hence by the Fredholm alternative theorem equation (2.8) has a unique $L^{2}$-solution $\varphi$ for each $g \in L^{2}(-1,1)$ if and only if the associated homogeneous equation has no nontrivial solutions in $L^{2}(-1,1)$.

If for a contradiction we assume that the homogeneous version of (2.8) has a nontrivial solution $\varphi \in L^{2}(-1,1)$, then from (2.7) it follows that

$$
u(x)=\frac{\varphi\left(\gamma^{-1}(x)\right)}{\gamma^{\prime}\left(\gamma^{-1}(x)\right)}
$$

satisfies (2.1) with $f \equiv 0$ and is not identically zero. Moreover, we have

$$
\int_{-1}^{1}|u(x)|^{p} d x=\int_{-1}^{1}\left|\frac{\varphi\left(\gamma^{-1}(x)\right)}{\gamma^{\prime}\left(\gamma^{-1}(x)\right)}\right|^{p} d x=\int_{-1}^{1} \frac{|\varphi(t)|^{p}}{\left|\gamma^{\prime}(t)\right|^{p-1}} d t
$$

hence by applying the Hölder inequality with indices $\frac{2}{p}$ and $\frac{2}{2-p}, 1<p<2$,

$$
\int_{-1}^{1}|u(x)|^{p} d x \leq\left(\int_{-1}^{1}|\varphi(t)|^{2} d t\right)^{\frac{p}{2}}\left(\int_{-1}^{1}\left|\gamma^{\prime}(t)\right|^{-2 \frac{(p-1)}{2-p}} d t\right)^{\frac{2-p}{2}}<\infty
$$

for all $p>1$ sufficiently close to 1 . But this contradicts our assumption that the original homogeneous equation has no nontrivial solutions $u \in L^{p}(-1,1)$, for any $p>1$.

\section{The Product-integration method}

In the case of equation (2.9), to define our product-integration method or Nyström type method, we replace the operators $K_{1}^{\gamma}$ and $K_{2}^{\gamma}$ in $\left(2.9^{\prime}\right)$ by

$$
K_{1, n}^{\gamma} \varphi(s)=\gamma^{\prime}(s) \sum_{i=1}^{n} w_{n i}^{\star}(s) \bar{h}_{1}\left(t_{n i}, s\right) \varphi\left(t_{n i}\right)
$$

\footnotetext{
${ }^{3}$ For the existence and uniqueness of solutions in the $L^{p}$-spaces, $p>1$, see for instance [7], [12].
} 
and

$$
K_{2, n}^{\gamma} \varphi(s)=\gamma^{\prime}(s) \sum_{i=1}^{n} \lambda_{n i}\left[\bar{h}_{1}\left(t_{n i}, s\right) \delta_{0}^{\star}\left(t_{n i}, s\right)+\bar{h}_{3}\left(t_{n i}, s\right)\right] \varphi\left(t_{n i}\right),
$$

respectively.

Rule (3.1) is an $n$-point product rule of interpolatory type, obtained by replacing $\bar{h}_{1}(t, s) \varphi(t)$ by its Lagrange interpolation polynomial (in the $t$-variable) associated with the Gauss Legendre nodes $\left\{t_{n i}\right\}$. Its coefficients $\left\{w_{n i}^{\star}(s)\right\}$ are given by the expression (see, for instance, [13])

$$
w_{n i}^{\star}(s)=\lambda_{n i} \sum_{j=0}^{n-1} h_{j}^{-1} \mu_{j}^{\star}(s) p_{j}\left(t_{n i}\right), \quad h_{j}=\int_{-1}^{1} p_{j}^{2}(t) d t=\frac{2}{2 j+1},
$$

where $\left\{\lambda_{n i}\right\}$ are the $n$-point Gauss-Legendre weights, $p_{j}(t)$ is the $j$-th degree orthogonal Legendre polynomial (normalized by the $h_{j}$ given above), and the quantities $\left\{\mu_{j}^{\star}(s)\right\}$ are given by the recurrence relationship (see [13])

$$
\left\{\begin{array}{l}
\mu_{0}^{\star}(s)=(1+s) \log (1+s)+(1-s) \log (1-s)-2, \\
\mu_{1}^{\star}(s)=\left(1-s^{2}\right) / 2 \log [(1-s) /(1+s)]-s, \\
(k+2) \mu_{k+1}^{\star}(s)=(2 k+1) s \mu_{k}^{\star}(s)-(k-1) \mu_{k-1}^{\star}(s), \quad k \geq 1 .
\end{array}\right.
$$

Rule (3.2) is simply the $n$-point Gauss-Legendre formula applied to the integral $K_{2}^{\gamma} \varphi(s)$.

In the case of equation (2.15), we replace $K_{1}^{\gamma}$ and $K_{2}^{\gamma}$ in it by

$$
K_{1, n}^{\gamma} \varphi(s)=\gamma^{\prime}(s) \sum_{i=1}^{n} w_{n i}^{(\alpha)}(s) \bar{h}_{2}\left(t_{n i}, s\right) \delta_{\alpha}\left(t_{n i}, s\right) \varphi\left(t_{n i}\right)
$$

and

$$
K_{2, n}^{\gamma} \varphi(s)=\gamma^{\prime}(s) \sum_{i=1}^{n} \lambda_{n i} \bar{h}_{3}\left(t_{n i}, s\right) \varphi\left(t_{n i}\right),
$$

respectively, where

$$
w_{n i}^{(\alpha)}(s)=\lambda_{n i} \sum_{j=0}^{n-1} h_{j}^{-1} \mu_{j}^{(\alpha)}(s) p_{j}\left(t_{n i}\right)
$$

with (see [13])

$$
\left\{\begin{array}{l}
\mu_{0}^{(\alpha)}(s)=\left[(1-s)^{1+\alpha}+(1+s)^{1+\alpha}\right] /(1+\alpha), \\
\mu_{1}^{(\alpha)}(s)=\left[(1-s)^{2+\alpha}-(1+s)^{2+\alpha}\right] /(2+\alpha)+s \mu_{0}^{(\alpha)}(s), \\
(k+2+\alpha) \mu_{k+1}^{(\alpha)}(s)=(2 k+1) s \mu_{k}^{(\alpha)}(s)-(k-1-\alpha) \mu_{k-1}^{(\alpha)}(s), \quad k \geq 1 .
\end{array}\right.
$$

Replacing the operator $K^{\gamma}=K_{1}^{\gamma}+K_{2}^{\gamma}$ in (2.9) or (2.15) by the above quadrature scheme, the product-integration method is characterized by collocating the approximate equation

$$
\left(I-K_{1, n}^{\gamma}-K_{2, n}^{\gamma}\right) \varphi_{n}(s)=g(s), \quad-1 \leq s \leq 1,
$$

at the points $s=t_{n j}, j=1, \ldots, n$, and solving the resulting linear system

$$
\left(I-K_{1, n}^{\gamma}-K_{2, n}^{\gamma}\right) \varphi_{n}\left(t_{n j}\right)=g\left(t_{n j}\right), \quad j=1, \ldots, n,
$$


for the unknowns $\left\{\varphi_{n}\left(t_{n j}\right)\right\}$. The product-integration approximant $\varphi_{n}(s)$ is then defined for all values of $s \in[-1,1]$ by the expression

$$
\varphi_{n}(s)=g(s)+K_{n}^{\gamma} \varphi_{n}(s),
$$

where $K_{n}^{\gamma}:=K_{1, n}^{\gamma}+K_{2, n}^{\gamma}$.

To derive a convergence estimate for the approximant (3.7) we need to examine the uniform behaviour of the Gauss-Legendre remainder term

$$
R_{n}^{G}(v ; s)=\int_{-1}^{1} v(t, s) d t-\sum_{i=1}^{n} \lambda_{n i} v\left(t_{n i}, s\right)
$$

and of the error

$$
R_{n}^{I}(v ; s)=\int_{-1}^{1} k(|t-s|) v(t, s) d t-\sum_{i=1}^{n} w_{n i}(s) v\left(t_{n i}, s\right)
$$

with $k$ defined as in (12)m generated by the product quadrature rules (3.1) and (3.4). For brevity, we have denoted by $\left\{w_{n i}(s)\right\}$ the weights of the latter rules. In particular, recalling the expressions of $K_{1}^{\gamma} \varphi$ and $K_{2}^{\gamma} \varphi$, we need to know these behaviours when $v(t, s) \in C^{l, \mu}\left([-1,1]^{2}\right)$ or $v(t, s)=h(t, s) z(t)$, where $h(t, s) \in$ $C^{l, \mu}\left([-1,1]^{2}\right)$, for some $0<\mu \leq 1$, and $z(t)$ is of the type $(1 \pm t)^{i} \log ^{j}(1 \pm t)$ with the integers $i \geq j \geq 1$ (see (1.4)), or of the type $(1 \pm t)^{\delta}$, with $\delta>0$ real, not an integer (see (2.13)).

To this aim, we recall the following well-known result (see, for instance, [9]):

$$
\left\|h-p_{n, n}\right\|_{\infty}=O\left(n^{-(l+\mu)}\right)
$$

which holds for every $h(t, s) \in C^{l, \mu}\left([-1,1]^{2}\right), p_{n, n}(t, s)$ being a best uniform algebraic approximating polynomial of degree $n$ separately in $t$ and in $s$.

Moreover, we reassemble in the next lemma some of the results obtained in [2] and [13], which are necessary to prove our main subsequent results.

Lemma 2. Let $k_{0}^{\star}$ and $k_{\alpha}$ be defined as in (1.2). For all integers $n$ there exist algebraic polynomials $q_{n}^{1}(t)$ and $q_{n}^{2}(t)$ of degree $n$, with $\left\|q_{n}^{i}\right\|_{\infty} \leq C,{ }^{4}$ such that the estimates

$$
\begin{gathered}
\int_{-1}^{1}\left|(1 \pm t)^{i} \log ^{j}(1 \pm t)-q_{n}^{1}(t)\right||k(|t-s|)| d t \\
\leq c \begin{cases}n^{-2 i-2+\varepsilon}, & \text { if } k=k_{0}^{\star} \text { or } k=k_{\alpha} \text { and } \alpha \geq 0, \\
n^{-2 i-2-2 \alpha+\varepsilon,}, & \text { if } k=k_{\alpha} \text { and } \alpha<0,\end{cases}
\end{gathered}
$$

with the integers $i \geq j \geq 1$, and

$$
\int_{-1}^{1}\left|(1 \pm t)^{\delta}-q_{n}^{2}(t)\right||k(|t-s|)| d t \leq c \begin{cases}n^{-2 \delta-2+\varepsilon}, & \text { if } k=k_{0}^{\star} \\ n^{-2 \delta-2}, & \text { if } k=k_{\alpha} \text { and } \alpha \geq 0 \\ n^{-2 \delta-2-2 \alpha}, & \text { if } k=k_{\alpha} \text { and } \alpha<0\end{cases}
$$

with $\delta>0$ real not integer, hold for $|s| \leq 1$, where $c$ is a constant independent of $s$ and $n$, and $\varepsilon$ denotes a positive real number as small as we like.

In the next lemma, we will describe the behaviours of the remainders (3.8) and (3.9), also generalizing some corresponding results in [13].

\footnotetext{
${ }^{4}$ The uniform boundedness of the polynomials $q_{n}^{i}$ follows from Theorems 1 and 3 in [2].
} 
Lemma 3. Assume in (3.9) either $k=k_{0}^{\star}$ or $k=k_{\alpha}$ with $\alpha>-\frac{3}{4}$ (see (1.2)). For the error terms $R_{n}^{X}(v ; s), X=G, I$, we have that:

if $v \in C^{l, \mu}\left([-1,1]^{2}\right)$, then

$$
\left\|R_{n}^{X}(v ; s)\right\|_{\infty}=O\left(n^{-(l+\mu)}\right)
$$

if $v(t, s)=h(t, s)(1 \pm t)^{i} \log ^{j}(1 \pm t)$ with $i \geq j \geq 1, h \in C^{2 i+1,1}\left([-1,1]^{2}\right)$, then

$$
\left\|R_{n}^{I}(v ; s)\right\|_{\infty}= \begin{cases}O\left(n^{-2 i-2+\varepsilon}\right), & \text { when } k=k_{0}^{\star} \text { or } k=k_{\alpha}, \alpha \geq 0, \\ O\left(n^{-2 i-2-2 \alpha+\varepsilon}\right), & \text { when } k=k_{\alpha},-\frac{3}{4}<\alpha<0\end{cases}
$$

if $v(t, s)=h(t, s)(1 \pm t)^{\delta}$, with $h \in C^{2\lceil\delta\rceil+1,1}\left([-1,1]^{2}\right)$ and $\delta$ a positive real, not integer, then

$$
\left\|R_{n}^{I}(v ; s)\right\|_{\infty}= \begin{cases}O\left(n^{-2 \delta-2+\varepsilon}\right), & \text { when } k=k_{0}^{\star} \text { or } k=k_{\alpha}, \alpha \geq 0, \\ O\left(n^{-2 \delta-2-2 \alpha+\varepsilon}\right), & \text { when } k=k_{\alpha},-\frac{3}{4}<\alpha<0 .\end{cases}
$$

In the estimates above $\varepsilon>0$ can be chosen arbitrarily small.

Proof. When $X=G$, the first assertion of the lemma is a straightforward consequence of (3.10); when $X=I,(3.11)$ follows from (3.10) and the fact that, under the assumptions on $k$, the weights $\left\{w_{n i}(s)\right\}$ satisfy the relation (see [23], [24])

$$
\lim _{n \rightarrow+\infty} \sum_{i=1}^{n}\left|w_{n i}(s)\right|=\int_{-1}^{1}|k(|t-s|)| d t<\infty
$$

uniformly with respect to $s$.

The function $v$ in (3.12) and (3.13) is expressed by a product of a smooth function $h(t, s)$, depending on two variables, and a function $z(t)$ which is at least continuous and depends only on one variable. Thus, we can write

$$
\left|h(t, s) z(t)-p_{r, r}(t, s) q_{r}(t)\right| \leq\left|h(t, s)\left(z(t)-q_{r}(t)\right)\right|+\left|q_{r}(t)\left(h(t, s)-p_{r, r}(t, s)\right)\right|,
$$

where $q_{r}$ is the polynomial defined by Lemma 2 and $p_{r, r}$ is that of (3.10), both of degree $r=\left\lceil\frac{n}{2}\right\rceil-1$.

From $\|h\|_{\infty} \leq c$ and $\left\|q_{r}\right\|_{\infty} \leq c$ (see Lemma 2), we have

$$
\left|h(t, s) z(t)-p_{r, r}(t, s) q_{r}(t)\right| \leq c\left[\left|z(t)-q_{r}(t)\right|+\left|h(t, s)-p_{r, r}(t, s)\right|\right] .
$$

Since $R_{n}^{X}(v ; s)=0$ whenever $v$ is a polynomial of degree $n-1$, we can write

$$
\begin{aligned}
\left|R_{n}^{X}(h z ; s)\right| & \leq \int_{-1}^{1}|k(|t-s|)|\left|h(t, s) z(t)-p_{r, r}(t, s) q_{r}(t)\right| d t \\
& +\int_{-1}^{1}|k(|t-s|)|\left|P_{n}\left(h(., s) z-p_{r, r}(., s) q_{r} ; t\right)\right| d t=: J_{1}+J_{2},
\end{aligned}
$$

where $P_{n}(f ; t)$ denotes the Lagrange polynomial interpolating $f$ at the zeros of the $n$-th degree Legendre polynomial. By virtue of (3.15), we have

$$
\begin{aligned}
J_{1} \leq c & {\left[\int_{-1}^{1}|k|(|t-s|)||\left|z(t)-q_{r}(t)\right| d t+\int_{-1}^{1}|k|(|t-s|)||\left|h(t, s)-p_{r, r}(t, s)\right| d t\right] } \\
& \leq c\left[\int_{-1}^{1}|k|(|t-s|)||\left|z(t)-q_{r}(t)\right| d t+\left\|h-p_{r, r}\right\|_{\infty}\right] .
\end{aligned}
$$

Using Lemma 2 and (3.10), we can bound the integral $J_{1}$. 
Next for $J_{2}$ we have

$$
\begin{aligned}
J_{2} & \leq \int_{-1}^{1}|k|(|t-s|)||\left|P_{n}\left(h(., s)\left(z-q_{r}\right) ; t\right)\right| d t \\
& +\int_{-1}^{1}|k|(|t-s|)||\left|P_{n}\left(q_{r}\left(h(., s)-p_{r, r}(., s)\right) ; t\right)\right| d t=: J_{2}^{(1)}+J_{2}^{(2)} .
\end{aligned}
$$

The integral $J_{2}^{(1)}$ can be estimated by proceeding as in the proof of the main theorems in [2], since $\|h\|_{\infty} \leq c$. In particular, one derives for $J_{2}^{(1)}$ bounds like those of Lemma 2. Moreover, by applying a Hölder inequality and taking into account the boundedness of the operator $P_{n}: C[-1,1] \rightarrow L^{p}(-1,1)$, with $1 \leq p<4$ (see $[16])$, we have

$$
\begin{aligned}
J_{2}^{(2)} & \leq\left(\int_{-1}^{1}|k|(|t-s|) \|^{q} d t\right)^{\frac{1}{q}}\left(\int_{-1}^{1}\left|P_{n}\left(q_{r}\left(h(., s)-p_{r, r}(., s)\right) ; t\right)\right|^{p} d t\right)^{\frac{1}{p}} \\
& \leq c\left\|h-p_{r, r}\right\|_{\infty},
\end{aligned}
$$

since we have assumed that $k=k_{0}^{\star}$ or $k=k_{\alpha}$ with $\alpha>-\frac{3}{4}$.

Combining the inequalities (3.16)-(3.19) with the assumptions of the lemma, we get the assertions (3.12) and (3.13) immediately.

Remark 1. Incidentally, we notice that the introduction of a smoothing change of variable like our $\gamma(t)$, defined in (2.4), can be a useful tool also when one has to compute a single integral

$$
\int_{-1}^{1} f(x) d x
$$

with $f(x)$ smooth everywhere in $[-1,1]$, except at a finite number of abscissas $-1 \equiv y_{0}<y_{1}<y_{2}<\ldots<y_{M}<y_{M+1} \equiv 1$ whose collocation is known a priori. In particular, when the behaviour of such irregularities is of the type (i) $\left(x-y_{k}\right)^{i} \log ^{j}\left|x-y_{k}\right|$ with $i \geq j \geq 1$, or (ii) $\left|x-y_{k}\right|^{\delta}$, with $\delta>0$ real, not an integer, ${ }^{5}$ by writing

$$
\int_{-1}^{1} f(x) d x=\sum_{k=0}^{M} \int_{y_{k}}^{y_{k+1}} f(\gamma(t)) \gamma^{\prime}(t) d t
$$

and applying, for example, an $n$-point Gauss-Legendre rule to each integral over $\left(y_{k}, y_{k+1}\right)$, we can obtain a rate of convergence $O\left(n^{-(i+1) \alpha_{k}-1+\varepsilon}\right)$ for each term of the type (i) and $O\left(n^{-(\delta+1) \alpha_{k}-1+\varepsilon}\right)$ for each of the type (ii).

In the next theorem, we prove the stability for our integration-product method and give an error estimate.

Theorem 1. Assume that the hypothesis of Lemma 1 and the assumptions on the functions $h_{i}(x, y), i=1,2,3$, and $f(y)$ (established at the beginning of Section 2) are fulfilled. Moreover, in (2.12) assume $\alpha>-\frac{3}{4}$. Let the equation $\left(I-K^{\gamma}\right) \varphi=g$ be defined as in $\left(2.8^{\prime}\right)$ or $\left(2.14^{\prime}\right)$. Then, for all sufficiently large integers $n$ the operator $I-K_{n}^{\gamma}$ is invertible in $C[-1,1]$ and

$$
\left\|\left(I-K_{n}^{\gamma}\right)^{-1}\right\|_{\infty} \leq c .
$$

\footnotetext{
${ }^{5}$ In principle, it would be sufficient to assume $\delta>-1$ (see [2]), but in practice, to see some real advantage we should assume $\delta$ not too close to -1 ; for example, $\delta \geq-1 / 2$.
} 
Moreover, given any integer $l$, if the parameters $\alpha_{k}, k=0, \ldots, M+1$, in (2.4) satisfy the conditions $\alpha_{k} \geq l+2$ in the case of (2.8') or $\alpha_{k} \geq 1+\frac{l}{1+\alpha}$ in the case of $\left(2.14^{\prime}\right),{ }^{6}$ for the approximate solution $\varphi_{n}$ defined by (3.7) the following estimate holds:

$$
\left\|\varphi-\varphi_{n}\right\|_{\infty} \leq \frac{c}{n^{l+\mu}}
$$

where $\mu=1-\varepsilon\left(\varepsilon>0\right.$ arbitrarily small) for (2.8') and $\mu=\left\lceil\frac{l}{1+\alpha}\right\rceil(1+\alpha)-l$ for $\left(2.14^{\prime}\right)$.

Proof. The properties of our equations $\left(2.8^{\prime}\right)$ and $\left(2.14^{\prime}\right)$ allow us to apply the theory developed in [22], hence claim that for all integers $n$ sufficiently large, the operator $I-K_{n}^{\gamma}$ is invertible in $C[-1,1]$ and $(3.20)$ holds uniformly respect to $n$. Standard arguments (see, for instance, [1]) then give the error bound

$$
\left\|\varphi-\varphi_{n}\right\|_{\infty} \leq c\left\|K^{\gamma} \varphi-K_{n}^{\gamma} \varphi\right\|_{\infty}
$$

i.e.

$$
\left\|\varphi-\varphi_{n}\right\|_{\infty} \leq c\left[\left\|K_{1}^{\gamma} \varphi-K_{1, n}^{\gamma} \varphi\right\|_{\infty}+\left\|K_{2}^{\gamma} \varphi-K_{2, n}^{\gamma} \varphi\right\|_{\infty}\right] .
$$

Taking into account the expressions of $K_{1}^{\gamma}$ and $K_{2}^{\gamma}$ defined in $\left(2.9^{\prime}\right)$ and $\left(2.15^{\prime}\right)$ and the expansion of $\varphi$, if the parameters $\alpha_{k}, k=0, \ldots, M+1$ satisfy the conditions of the theorem, we can bound both terms on the right-hand side of (3.22) by $O\left(n^{-(l+\mu)}\right)$.

Remark 2. The restriction $\alpha>-\frac{3}{4}$ is due to the fact that we have applied the results obtained by Sloan in [22]; there, the above condition on the kernel $k_{\alpha}$, together with another one, is sufficient to prove the stability of a product-integration method with polynomials and zeros of Jacobi polynomials. However, we have tested the method also for some values of $\alpha$ less than or equal to $-\frac{3}{4}$ and have not found any phenomenon of numerical instability. Also in Lemma 3, we have assumed the same restriction on $\alpha$, because it is sufficient to guarantee the relation (3.14). In both cases, the assumption on $\alpha$ represents a sufficient, but not necessary, condition. Therefore, supported by our numerical results, we think that Theorem 1 holds for every $\alpha>-1$. Moreover, the conditions $\alpha_{k} \geq l+2$ and $\alpha_{k} \geq 1+\frac{l}{1+\alpha}, k=$ $0, \ldots, M+1$, guarantee that the functions $\delta_{0}^{\star}(t, s) \gamma^{\prime}(s)$ and $\delta_{\alpha}(t, s) \gamma^{\prime}(s)$ (see (2.9), (2.15)) respectively, belong to the space $C^{l, \mu}\left([-1,1]^{2}\right)$ for some $0<\mu \leq 1$, hence that $\left\|K_{1}^{\gamma} \varphi-K_{1, n}^{\gamma} \varphi\right\|_{\infty}$ and $\left\|K_{2}^{\gamma} \varphi-K_{2, n}^{\gamma} \varphi\right\|_{\infty}$ in (3.22) behave like $O\left(n^{-l-\mu}\right)$ as $n \rightarrow \infty$. In particular, the above conditions for $k=0, M+1$ are necessary to assure the desired smoothness at the points $s=t= \pm 1$. Nevertheless, in practice, as we shall see in the numerical examples of Section $5, \alpha_{0}$ and $\alpha_{M+1}$ can be chosen smaller. More precisely, recalling the endpoint superconvergence phenomenon proved in [2], we conjecture that for the above quadrature errors an estimate similar to (3.12) holds even when $\alpha_{0}=\alpha_{1}=\left\lceil\frac{l+1}{2}\right\rceil$ if $M=0$ or $\alpha_{0}=\alpha_{M+1}=\left\lceil\frac{\alpha_{k}-1}{2}\right\rceil$ if $M>0$, where $\alpha_{k}=l+2$ or $\alpha_{k}=1+\left\lceil\frac{l}{1+\alpha}\right\rceil, k=1, \ldots, M$, respectively.

Remark 3. We have not explicitly considered equation (1.1) with the more general kernel (1.3) merely to simplify the description. Indeed, Lemma 1 and the proof of stability in Theorem 1 remain true also in the case of a more general kernel of form

\footnotetext{
${ }^{6}$ In effect, one chooses $\alpha_{k}=l+2$ in the first case and $\alpha_{k}=1+\left\lceil\frac{l}{1+\alpha}\right\rceil$ in the second case, for every $k \in\{0, \ldots, M+1\}$; see, however, Remark 2 .
} 
(1.3). However, to select the correct values of the parameters $\left\{\alpha_{k}\right\}$ and hence derive optimal error estimates, one needs to know the proper expansion of the solution $u(x)$ of (1.1); in the general case this expansion is cumbersome to obtain.

\section{The COllocation Method}

In the sequel, by $P_{n}$ we will denote the Lagrange interpolation projector associated with the zeros of the $n$-th degree Legendre polynomial $p_{n}(x)$. The collocation method we consider is given by the equation

$$
\left(I-P_{n} K^{\gamma}\right) \varphi_{n}=P_{n} g, \quad \varphi_{n} \in \Pi_{n-1},
$$

where $\Pi_{n-1}$ is the set of all polynomials of degree less than or equal to $n-1$.

We shall examine our method in the space $L^{2}(-1,1)$; in particular, there we will prove its stability and derive a convergence estimate. Some preliminary results are needed, however.

Lemma 4. Let $v \in L^{2}(-1,1)$ and define

$$
g(y):=\int_{-1}^{1} h(x, y) k(|x-y|) v(x) d x
$$

where $h(x, y) \in C^{\mu}\left([-1,1]^{2}\right), 0<\mu \leq 1,{ }^{7}$ and $k=k_{0}^{\star}$ or $k=k_{\alpha}$ with $\alpha>-\frac{1}{2}$ (see (1.2)). Then $g(y) \in C^{\varepsilon}[-1,1]$ for some $\varepsilon>0$, and

$$
\|g\|_{C^{\varepsilon}} \leq c\|v\|_{L^{2}} .
$$

Proof. For $y_{1}, y_{2} \in[-1,1], y_{1} \neq y_{2}$, we have

$$
\begin{aligned}
g\left(y_{1}\right)-g\left(y_{2}\right) & =\int_{-1}^{1}\left[h\left(x, y_{1}\right)-h\left(x, y_{2}\right)\right] k\left(\left|x-y_{1}\right|\right) v(x) d x \\
& +\int_{-1}^{1} h\left(x, y_{2}\right)\left[k\left(\left|x-y_{1}\right|\right)-k\left(\left|x-y_{2}\right|\right)\right] v(x) d x=: I_{1}+I_{2},
\end{aligned}
$$

By the assumptions on $h$ and $\alpha$, and Schwarz's inequality, we immediately obtain the bound

$$
\left|I_{1}\right| \leq c\left|y_{1}-y_{2}\right|^{\mu} \int_{-1}^{1}\left|k\left(\left|x-y_{1}\right|\right)\right||v(x)| d x \leq c\left|y_{1}-y_{2}\right|^{\mu}\|v\|_{L^{2}} .
$$

To bound $I_{2}$ we need to consider the three cases $k=k_{0}^{\star}, k=k_{\alpha}$ with $-\frac{1}{2}<\alpha<0$, and $k=k_{\alpha}$ with $\alpha \geq 0$, separately.

In the first case $\left(k=k_{0}^{\star}\right)$, we set

$$
\psi(x):=h\left(x, y_{2}\right) v(x) \in L^{2}(-1,1)
$$

and

$$
G(y):=\int_{-1}^{1} \log |x-y| \psi(x) d x
$$

We have

$$
G^{\prime}(y)=\int_{-1}^{1} \frac{\psi(x)}{x-y} d x \in L^{2}(-1,1)
$$

\footnotetext{
${ }^{7}$ In the integral equations we are considering, our kernel $h$ is actually $C^{\infty}$.
} 
where the integral is defined in the Cauchy principal value sense; hence

$$
I_{2}=G\left(y_{1}\right)-G\left(y_{2}\right)=\int_{y_{2}}^{y_{1}} G^{\prime}(x) d x .
$$

By applying Schwarz's inequality, we obtain

$$
\left|I_{2}\right|^{2} \leq \int_{y_{2}}^{y_{1}}\left|G^{\prime}(x)\right|^{2} d x\left|\int_{y_{2}}^{y_{1}} d x\right| \leq\left|y_{1}-y_{2}\right|\left\|G^{\prime}\right\|_{L^{2}}^{2} .
$$

Since the operator $G^{\prime}$ is bounded on $L^{2}(-1,1)$ (see, for instance, [12]), i.e., $\left\|G^{\prime}\right\|_{L^{2}} \leq$ $c\|\psi\|_{L^{2}}$, and $\|\psi\|_{L^{2}} \leq c\|v\|_{L^{2}}$, from (4.3) and (4.4) it follows that $g \in C^{\lambda}$, with $\lambda=\min \left\{\mu, \frac{1}{2}\right\}$, and that (4.2) holds.

Now, we turn to the case $k=k_{\alpha}$ with $-\frac{1}{2}<\alpha<0$. Using the well-known inequality

$$
\left|a^{\gamma}-b^{\gamma}\right| \leq|a-b|^{\gamma}
$$

which holds for any positive numbers $a$ and $b$, and $0 \leq \gamma \leq 1$, we have

$$
\begin{aligned}
\left|I_{2}\right| & \leq c \int_{-1}^{1} \frac{\left|y_{1}-y_{2}\right|^{-\alpha}}{\left|x-y_{1}\right|^{-\alpha}\left|x-y_{2}\right|^{-\alpha}}|v(x)| d x \\
& \leq c\left|y_{1}-y_{2}\right|^{\varepsilon} \int_{-1}^{1} \frac{\left|y_{1}-y_{2}\right|^{-\alpha-\varepsilon}}{\left|x-y_{1}\right|^{-\alpha}\left|x-y_{2}\right|^{-\alpha}}|v(x)| d x \\
& \leq c\left|y_{1}-y_{2}\right|^{\varepsilon}\left[\int_{-1}^{1} \frac{|v(x)|}{\left|x-y_{1}\right|^{-\alpha}\left|x-y_{2}\right|^{\varepsilon}} d x+\int_{-1}^{1} \frac{|v(x)|}{\left|x-y_{1}\right|^{\varepsilon}\left|x-y_{2}\right|^{-\alpha}} d x\right],
\end{aligned}
$$

the last estimate being a consequence of the uniform boundedness of the function

$$
\frac{\left|y_{1}-y_{2}\right|^{-\alpha-\varepsilon}}{\left|x-y_{1}\right|^{-\alpha-\varepsilon}+\left|x-y_{2}\right|^{-\alpha-\varepsilon}} \text {. }
$$

By taking $0<\varepsilon<\frac{1}{2}+\alpha$ and applying Schwarz's inequality to the last bound for $\left|I_{2}\right|$, we obtain

$$
\left|I_{2}\right| \leq c\left|y_{1}-y_{2}\right|^{\varepsilon}\|v\|_{L^{2}} .
$$

From (4.3) and (4.5) the assertion of the lemma follows in the case $k=k_{\alpha}$ with $-\frac{1}{2}<\alpha<0$.

Finally, in the case that $k=k_{\alpha}$ and $\alpha \geq 0$, it is sufficient to set for $\alpha>0$

$$
\bar{\psi}(x, y):=h(x, y) k(|x-y|) \in C^{\nu}[-1,1]
$$

with $\nu=\min \{\mu, \alpha\}$ (for $\alpha=0$ this setting is superfluous, since $k=1$ ), and notice that

$$
\left|g\left(y_{1}\right)-g\left(y_{2}\right)\right| \leq \int_{-1}^{1}\left|\bar{\psi}\left(x, y_{1}\right)-\bar{\psi}\left(x, y_{2}\right)\right||v(x)| d x \leq c\left|y_{1}-y_{2}\right|^{\nu} \int_{-1}^{1}|v(x)| d x
$$

with $g \in C^{\mu}$ if $\alpha=0, g \in C^{\nu}$ if $\alpha>0$.

This complete our proof.

Remark 4. The restriction $\alpha>-\frac{1}{2}$ is due to the fact that we are examining our equation in the space $L^{2}(-1,1)$. Of course we would be interested in considering the whole range $\alpha>-1$, but this would necessarily mean that we should work in a different space, which till now we have not been able to find. 
Lemma 5 (see Theorem 3.1 in [11]). Let $v \in C^{l, \mu}[-1,1], l \geq 0,0<\mu \leq 1$. Then

$$
\left\|v-P_{n} v\right\|_{L^{2}} \leq \frac{c}{n^{l+\mu}}
$$

with a constant $c$ independent of $n$.

With the above two lemmas we are able to prove the stability of our collocation method, hence derive an $L^{2}$-convergence estimate.

Theorem 2. Assume that the hypothesis of Lemma 1 and the assumptions on the functions $h_{i}(x, y), i=1,2,3$, and $f(y)$ (established at the beginning of Section 2) are fulfilled. Moreover, in (2.12) assume $\alpha>-\frac{1}{2}$. Let the equation $\left(I-K^{\gamma}\right) \varphi=g$ be defined as in (2.8') or (2.14'). Then, for all sufficiently large integers $n$ the operator $\left(I-P_{n} K^{\gamma}\right)$ is invertible in $L^{2}(-1,1)$ and

$$
\left\|\left(I-P_{n} K^{\gamma}\right)^{-1}\right\|_{L^{2}} \leq c .
$$

Moreover, given any integer $l$, if the parameters $\alpha_{k}, k=0, \ldots, M+1$, in (2.4) satisfy the conditions $\alpha_{k} \geq l+2$ in the case of (2.8') or $\alpha_{k} \geq 1+\frac{l}{1+\alpha}$ in the case of (2.14'), for the approximate solution $\varphi_{n}$ defined by (4.1) the following estimate holds:

$$
\left\|\varphi-\varphi_{n}\right\|_{L^{2}} \leq \frac{c}{n^{l+\mu}}
$$

where $\mu=1-\varepsilon\left(\varepsilon>0\right.$ arbitrarily small) for (2.8') and $\mu=\left\lceil\frac{l}{1+\alpha}\right\rceil(1+\alpha)-l$ for (2.14').

Proof. Lemma 4 ensures that the operator $K^{\gamma}: L^{2} \rightarrow C^{\varepsilon}$ is bounded for some $\varepsilon>0$. Moreover, it is well-known that the space $C^{\varepsilon}$ is compactly embedded in $C^{\varepsilon^{\prime}}$, for any $0<\varepsilon^{\prime} \leq \varepsilon$. Thus $K^{\gamma}: L^{2} \rightarrow C^{\varepsilon^{\prime}}$ is certainly compact. From Lemma 5, we also have that $\left\|\left(I-P_{n}\right) v\right\|_{L^{2}}$ converges to zero as $n \rightarrow \infty$ whenever $v \in C^{\varepsilon^{\prime}}$. Therefore standard theory (see, for example, [1]) allows us to claim that $\left\|\left(I-P_{n}\right) K^{\gamma}\right\|_{L^{2}} \rightarrow 0$ as $n \rightarrow \infty$, hence that (4.6) holds for all sufficiently large $n$, provided that the operator $I-K^{\gamma}$ is invertible in $L^{2}(-1,1)$.

Once we know that (4.6) holds, then the derivation of the following error estimate is fairly straightforward (see [1]):

$$
\left\|\varphi-\varphi_{n}\right\|_{L^{2}} \leq c\left\|\varphi-P_{n} \varphi\right\|_{L^{2}}
$$

If the parameters $\alpha_{k}, k=0, \ldots, M+1$, satisfy the conditions of the theorem, we have that $\varphi \in C^{l, \mu}[-1,1]$, with $\mu$ depending on the degree of singularity of the kernel function considered. Therefore, the bound (4.7) follows from Lemma 5.

Remark 5. Following the same machinery used in [10], we can obtain from (4.7) a uniform error estimate. Indeed, given any polynomial $q_{n}(x)$ of degree $n-1$, if we expand it in series of Legendre orthonormal polynomials $\left\{p_{n}(x)\right\}$ we obtain

$$
q_{n}(x)=\sum_{k=0}^{n-1} c_{k} p_{k}(x), \quad c_{k}=\int_{-1}^{1} q_{n}(x) p_{k}(x) d x .
$$

Then, proceeding exactly as in [10], we obtain first the inequalities

$$
\begin{gathered}
\left\|q_{n}\right\|_{\infty} \leq c n\left\|q_{n}\right\|_{L^{2}}, \\
\max _{x \in \Delta}\left|q_{n}(x)\right| \leq c \sqrt{n}\left\|q_{n}\right\|_{L^{2}},
\end{gathered}
$$


$\Delta$ being any closed subset of $(-1,1)$, and then, for our solution $\varphi_{n}$, the error estimates

$$
\begin{gathered}
\left\|\varphi-\varphi_{n}\right\|_{\infty} \leq \frac{c}{n^{l+\mu-3 / 2-\varepsilon}}, \quad l+\mu>\frac{3}{2}, \\
\max _{x \in \Delta}\left|\varphi(x)-\varphi_{n}(x)\right| \leq \frac{c}{n^{l+\mu-1-\varepsilon}}, \quad l+\mu>1,
\end{gathered}
$$

where $\varepsilon>0$ can be chosen arbitrarily small.

Finally, we point out that a comment like Remark 3 holds also for the collocation method.

\section{NumeriCAL EXAMPLES}

To test the efficiency of our numerical approaches, we have applied the methods defined in Sections 3 and 4, to equations of the type (2.1) and (2.12) with input functions $f(y)=y,|y|, \operatorname{sgn}(y)$. For simplicity, in $(2.1)$ we have taken $h_{1}(x, y)$ equal to a constant (for example, $\left.h_{1}(x, y) \equiv \frac{1}{\pi}\right)$ and $h_{3}(x, y) \equiv 0$. Analogously, in (2.12) we have set $h_{2}(x, y) \equiv \frac{1}{\pi}$ and $h_{3}(x, y) \equiv 0$.

In Tables 2, 3 and 4, we give a few of the absolute errors we have obtained when our equations of the type (2.9) were solved by the product-integration method described in Section 3. In Table 5, we report the relative errors of the solution $u$ of the original equation (2.1), obtained using the same values of $\alpha_{k}$ used in Table 4. To compute all these errors, we have taken as reference value the approximation we obtained with $n=256$ points. In the following, the symbol $C N$ will denote the estimated condition number.

By examining the values of Tables 2 and 3, we immediately notice a drawback of our smoothing technique. Although in theory by taking the $\alpha_{k}$ 's sufficiently large we can obtain an arbitrarily high rate of convergence, in practice larger values of the $\alpha_{k}$ 's also mean increasing flatness of $\gamma(t)$ around the $y_{k}$ 's. This implies, particularly for low values of $n$, that higher values of the $\alpha_{k}$ 's do not necessarily mean higher accuracy. Nevertheless the final linear systems one has to solve are perfectly

TABLE 2. Values of $\left|\varphi_{256}(s)-\varphi_{n}(s)\right|$ obtained by the productintegration method applied to (2.9) when $f(y)=y$.

\begin{tabular}{|c|c|c|c|c|c|c|c|c|}
\hline$s$ & $\alpha_{0}$ & $\alpha_{1}$ & $n=4$ & $n=8$ & $n=16$ & $n=32$ & $n=64$ & $n=128$ \\
\hline \hline 0.1 & 2 & 2 & $1.2 \mathrm{E}-02$ & $4.3 \mathrm{E}-05$ & $9.3 \mathrm{E}-10$ & $1.3 \mathrm{E}-11$ & $1.6 \mathrm{E}-13$ & $4.0 \mathrm{E}-15$ \\
\hline \hline & 3 & 3 & $6.4 \mathrm{E}-02$ & $1.2 \mathrm{E}-03$ & $4.1 \mathrm{E}-07$ & $3.1 \mathrm{E}-13$ & $7.2 \mathrm{E}-15$ & $9.6 \mathrm{E}-15$ \\
\hline & 4 & 4 & $1.5 \mathrm{E}-01$ & $6.6 \mathrm{E}-03$ & $9.6 \mathrm{E}-06$ & $4.6 \mathrm{E}-12$ & $1.0 \mathrm{E}-14$ & $1.3 \mathrm{E}-14$ \\
\hline & 5 & 5 & $2.3 \mathrm{E}-01$ & $2.1 \mathrm{E}-02$ & $6.9 \mathrm{E}-05$ & $2.7 \mathrm{E}-10$ & $8.4 \mathrm{E}-15$ & $1.2 \mathrm{E}-14$ \\
\hline \hline 0.5 & 2 & 2 & $8.3 \mathrm{E}-02$ & $5.6 \mathrm{E}-05$ & $1.6 \mathrm{E}-08$ & $9.5 \mathrm{E}-11$ & $3.5 \mathrm{E}-13$ & $8.9 \mathrm{E}-16$ \\
\hline & 3 & 3 & $3.1 \mathrm{E}-01$ & $1.4 \mathrm{E}-03$ & $9.3 \mathrm{E}-07$ & $1.1 \mathrm{E}-13$ & $1.3 \mathrm{E}-15$ & $2.7 \mathrm{E}-15$ \\
\hline & 4 & 4 & $5.3 \mathrm{E}-01$ & $6.9 \mathrm{E}-03$ & $1.4 \mathrm{E}-05$ & $1.9 \mathrm{E}-12$ & $8.9 \mathrm{E}-16$ & $3.1 \mathrm{E}-15$ \\
\hline & 5 & 5 & $6.5 \mathrm{E}-01$ & $1.7 \mathrm{E}-02$ & $6.6 \mathrm{E}-05$ & $7.9 \mathrm{E}-11$ & $4.4 \mathrm{E}-16$ & $3.3 \mathrm{E}-15$ \\
\hline \hline 0.9 & 2 & 2 & $6.2 \mathrm{E}-03$ & $8.3 \mathrm{E}-05$ & $5.4 \mathrm{E}-08$ & $8.5 \mathrm{E}-11$ & $4.9 \mathrm{E}-14$ & $1.9 \mathrm{E}-15$ \\
\hline & 3 & 3 & $8.0 \mathrm{E}-03$ & $2.6 \mathrm{E}-04$ & $6.6 \mathrm{E}-08$ & $1.1 \mathrm{E}-13$ & $0.0 \mathrm{E}+00$ & $8.3 \mathrm{E}-17$ \\
\hline & 4 & 4 & $4.7 \mathrm{E}-03$ & $2.0 \mathrm{E}-04$ & $2.3 \mathrm{E}-07$ & $3.1 \mathrm{E}-14$ & $3.1 \mathrm{E}-17$ & $3.5 \mathrm{E}-18$ \\
\hline & 5 & 5 & $1.7 \mathrm{E}-03$ & $9.8 \mathrm{E}-05$ & $2.4 \mathrm{E}-07$ & $2.6 \mathrm{E}-13$ & $1.7 \mathrm{E}-17$ & $1.1 \mathrm{E}-17$ \\
\hline
\end{tabular}


TABLE 3. Values of $\left|\varphi_{256}(s)-\varphi_{n}(s)\right|$ obtained by the productintegration method applied to $(2.9)$ when $f(y)=|y|$.

\begin{tabular}{|c|c|c|c|c|c|c|c|c|c|}
\hline$s$ & $\alpha_{0}$ & $\alpha_{1}$ & $\alpha_{2}$ & $n=4$ & $n=8$ & $n=16$ & $n=32$ & $n=64$ & $n=128$ \\
\hline \hline 0.1 & 2 & 5 & 2 & $7.8 \mathrm{E}-04$ & $8.4 \mathrm{E}-04$ & $3.0 \mathrm{E}-07$ & $1.6 \mathrm{E}-09$ & $7.3 \mathrm{E}-11$ & $2.7 \mathrm{E}-13$ \\
\hline & 3 & 7 & 3 & $9.0 \mathrm{E}-05$ & $3.2 \mathrm{E}-06$ & $1.5 \mathrm{E}-08$ & $7.4 \mathrm{E}-11$ & $1.3 \mathrm{E}-12$ & $2.4 \mathrm{E}-15$ \\
\hline & 4 & 9 & 4 & $7.1 \mathrm{E}-06$ & $7.9 \mathrm{E}-07$ & $7.9 \mathrm{E}-09$ & $1.1 \mathrm{E}-11$ & $3.4 \mathrm{E}-14$ & $6.8 \mathrm{E}-17$ \\
\hline & 5 & 11 & 5 & $5.0 \mathrm{E}-07$ & $1.0 \mathrm{E}-07$ & $1.6 \mathrm{E}-09$ & $2.8 \mathrm{E}-12$ & $3.4 \mathrm{E}-16$ & $3.6 \mathrm{E}-18$ \\
\hline \hline 0.5 & 2 & 5 & 2 & $1.3 \mathrm{E}-01$ & $7.7 \mathrm{E}-03$ & $9.8 \mathrm{E}-05$ & $1.1 \mathrm{E}-07$ & $1.9 \mathrm{E}-09$ & $3.1 \mathrm{E}-11$ \\
\hline & 3 & 7 & 3 & $2.6 \mathrm{E}-01$ & $3.6 \mathrm{E}-02$ & $5.7 \mathrm{E}-04$ & $4.2 \mathrm{E}-09$ & $7.4 \mathrm{E}-11$ & $3.7 \mathrm{E}-13$ \\
\hline & 4 & 9 & 4 & $3.3 \mathrm{E}-01$ & $8.3 \mathrm{E}-02$ & $1.4 \mathrm{E}-03$ & $1.5 \mathrm{E}-07$ & $3.6 \mathrm{E}-12$ & $1.8 \mathrm{E}-15$ \\
\hline & 5 & 11 & 5 & $3.6 \mathrm{E}-01$ & $1.3 \mathrm{E}-01$ & $2.5 \mathrm{E}-03$ & $2.9 \mathrm{E}-07$ & $9.3 \mathrm{E}-12$ & $2.2 \mathrm{E}-15$ \\
\hline \hline 0.9 & 2 & 5 & 2 & $2.1 \mathrm{E}-01$ & $4.1 \mathrm{E}-03$ & $1.3 \mathrm{E}-04$ & $1.0 \mathrm{E}-11$ & $5.0 \mathrm{E}-10$ & $7.8 \mathrm{E}-12$ \\
\hline & 3 & 7 & 3 & $2.2 \mathrm{E}-01$ & $5.4 \mathrm{E}-02$ & $3.7 \mathrm{E}-04$ & $1.3 \mathrm{E}-09$ & $2.3 \mathrm{E}-12$ & $5.8 \mathrm{E}-14$ \\
\hline & 4 & 9 & 4 & $1.5 \mathrm{E}-01$ & $7.4 \mathrm{E}-02$ & $1.3 \mathrm{E}-03$ & $2.6 \mathrm{E}-07$ & $1.7 \mathrm{E}-12$ & $4.0 \mathrm{E}-15$ \\
\hline & 5 & 11 & 5 & $7.5 \mathrm{E}-02$ & $6.7 \mathrm{E}-02$ & $1.9 \mathrm{E}-03$ & $1.0 \mathrm{E}-06$ & $2.6 \mathrm{E}-12$ & $2.4 \mathrm{E}-15$ \\
\hline
\end{tabular}

TABLE 4. Values of $\left|\varphi_{256}(s)-\varphi_{n}(s)\right|$ obtained by the productintegration method $\left(\alpha_{0} \equiv \alpha_{2}=3, \alpha_{1}=7\right)$ applied to (2.9) when $f(y)=\operatorname{sgn}(y)$.

\begin{tabular}{|c|c|c|c|c|c|c|c|}
\hline$s$ & $\varphi_{256}(s)$ & $n=4$ & $n=8$ & $n=16$ & $n=32$ & $n=64$ & $n=128$ \\
\hline \hline 0.1 & $1.491312275276053 \mathrm{E}-03$ & $5.8 \mathrm{E}-04$ & $2.3 \mathrm{E}-06$ & $1.5 \mathrm{E}-07$ & $1.5 \mathrm{E}-09$ & $1.9 \mathrm{E}-11$ & $3.7 \mathrm{E}-14$ \\
\hline 0.2 & $7.541252814922007 \mathrm{E}-02$ & $2.9 \mathrm{E}-02$ & $1.0 \mathrm{E}-03$ & $2.3 \mathrm{E}-05$ & $7.6 \mathrm{E}-08$ & $1.1 \mathrm{E}-10$ & $1.6 \mathrm{E}-13$ \\
\hline 0.3 & $6.576626868598414 \mathrm{E}-01$ & $2.6 \mathrm{E}-01$ & $2.0 \mathrm{E}-02$ & $1.0 \mathrm{E}-04$ & $2.3 \mathrm{E}-07$ & $3.2 \mathrm{E}-10$ & $9.1 \mathrm{E}-13$ \\
\hline 0.4 & $2.714004335731008 \mathrm{E}+00$ & $1.1 \mathrm{E}+00$ & $9.7 \mathrm{E}-02$ & $6.0 \mathrm{E}-04$ & $1.9 \mathrm{E}-07$ & $8.0 \mathrm{E}-10$ & $2.6 \mathrm{E}-12$ \\
\hline 0.5 & $7.163017124263911 \mathrm{E}+00$ & $3.0 \mathrm{E}+00$ & $9.3 \mathrm{E}-02$ & $2.5 \mathrm{E}-03$ & $4.0 \mathrm{E}-07$ & $1.2 \mathrm{E}-09$ & $5.7 \mathrm{E}-12$ \\
\hline 0.6 & $1.337727347069014 \mathrm{E}+01$ & $5.5 \mathrm{E}+00$ & $3.6 \mathrm{E}-01$ & $1.8 \mathrm{E}-03$ & $7.6 \mathrm{E}-07$ & $1.6 \mathrm{E}-09$ & $8.7 \mathrm{E}-12$ \\
\hline 0.7 & $1.743322199231756 \mathrm{E}+01$ & $6.4 \mathrm{E}+00$ & $7.8 \mathrm{E}-01$ & $1.0 \mathrm{E}-02$ & $9.6 \mathrm{E}-08$ & $2.6 \mathrm{E}-09$ & $8.0 \mathrm{E}-12$ \\
\hline 0.8 & $1.414225464371011 \mathrm{E}+01$ & $3.2 \mathrm{E}+00$ & $7.1 \mathrm{E}-02$ & $8.7 \mathrm{E}-03$ & $1.1 \mathrm{E}-07$ & $4.4 \mathrm{E}-10$ & $4.1 \mathrm{E}-12$ \\
\hline 0.9 & $5.386587260789846 \mathrm{E}+00$ & $2.6 \mathrm{E}+00$ & $2.6 \mathrm{E}-01$ & $3.2 \mathrm{E}-03$ & $1.2 \mathrm{E}-08$ & $1.8 \mathrm{E}-11$ & $7.4 \mathrm{E}-13$ \\
\hline$C N$ & & $2.3 \mathrm{E}+00$ & $3.9 \mathrm{E}+00$ & $3.9 \mathrm{E}+00$ & $4.6 \mathrm{E}+00$ & $4.7 \mathrm{E}+00$ & $4.7 \mathrm{E}+00$ \\
\hline
\end{tabular}

TABLE 5. Values of $\left|u_{256}(y)-u_{n}(y)\right| /\left|u_{256}(y)\right|$ obtained by the product-integration method $\left(\alpha_{0} \equiv \alpha_{2}=3, \alpha_{1}=7\right)$ applied to (2.9) when $f(y)=\operatorname{sgn}(y)$.

\begin{tabular}{|c|c|c|c|c|c|c|c|}
\hline$y$ & $u_{256}(y)$ & $n=4$ & $n=8$ & $n=16$ & $n=32$ & $n=64$ & $n=128$ \\
\hline 0.1 & $1.346827752778405 \mathrm{E}+00$ & $4.9 \mathrm{E}-02$ & $1.1 \mathrm{E}-02$ & $4.7 \mathrm{E}-04$ & $1.6 \mathrm{E}-09$ & $1.0 \mathrm{E}-09$ & $3.9 \mathrm{E}-12$ \\
\hline 0.2 & $1.591034197365066 \mathrm{E}+00$ & $9.3 \mathrm{E}-02$ & $2.3 \mathrm{E}-02$ & $2.9 \mathrm{E}-04$ & $3.3 \mathrm{E}-08$ & $5.2 \mathrm{E}-10$ & $7.3 \mathrm{E}-13$ \\
\hline 0.3 & $1.784057498883805 \mathrm{E}+00$ & $1.1 \mathrm{E}-01$ & $2.9 \mathrm{E}-02$ & $3.2 \mathrm{E}-04$ & $6.4 \mathrm{E}-08$ & $5.7 \mathrm{E}-10$ & $2.4 \mathrm{E}-12$ \\
\hline 0.4 & $1.934456855253425 \mathrm{E}+00$ & $1.1 \mathrm{E}-01$ & $2.9 \mathrm{E}-02$ & $6.8 \mathrm{E}-04$ & $1.6 \mathrm{E}-08$ & $3.7 \mathrm{E}-10$ & $9.3 \mathrm{E}-13$ \\
\hline 0.5 & $2.044820766513727 \mathrm{E}+00$ & $9.8 \mathrm{E}-02$ & $2.2 \mathrm{E}-02$ & $5.6 \mathrm{E}-04$ & $2.6 \mathrm{E}-08$ & $2.4 \mathrm{E}-10$ & $2.6 \mathrm{E}-14$ \\
\hline 0.6 & $2.115382890662598 \mathrm{E}+00$ & $6.8 \mathrm{E}-02$ & $9.0 \mathrm{E}-03$ & $4.7 \mathrm{E}-05$ & $9.0 \mathrm{E}-09$ & $1.2 \mathrm{E}-10$ & $7.9 \mathrm{E}-13$ \\
\hline 0.7 & $2.144773613992187 \mathrm{E}+00$ & $2.0 \mathrm{E}-02$ & $9.7 \mathrm{E}-03$ & $5.7 \mathrm{E}-04$ & $7.5 \mathrm{E}-09$ & $5.8 \mathrm{E}-11$ & $1.4 \mathrm{E}-12$ \\
\hline 0.8 & $2.129502912442114 \mathrm{E}+00$ & $5.3 \mathrm{E}-02$ & $3.3 \mathrm{E}-02$ & $7.6 \mathrm{E}-04$ & $1.2 \mathrm{E}-09$ & $3.1 \mathrm{E}-10$ & $5.3 \mathrm{E}-13$ \\
\hline 0.9 & $2.060852904622524 \mathrm{E}+00$ & $1.7 \mathrm{E}-01$ & $5.7 \mathrm{E}-02$ & $7.5 \mathrm{E}-05$ & $5.5 \mathrm{E}-09$ & $1.6 \mathrm{E}-10$ & $9.7 \mathrm{E}-13$ \\
\hline$C N$ & & $2.3 \mathrm{E}+00$ & $3.9 \mathrm{E}+00$ & $3.9 \mathrm{E}+00$ & $4.6 \mathrm{E}+00$ & $4.7 \mathrm{E}+00$ & $4.7 \mathrm{E}+00$ \\
\hline
\end{tabular}

conditioned, and the accuracy given by our product-integration method is much higher than that of corresponding product-integration and Galerkin methods, constructed on graded meshes (see Tables 6, 7 and 8). These latter two methods have been applied by subdividing the interval of integration into $N$ parts, with grading exponent $q$ (see [21], [26]), and using $d+1$ interpolation points in each subinterval. These nodes are the Gauss-Legendre ones. Notice that the order of the final linear system is $N(d+1)$. As regards their implementation, we have to remark that for little values of $d$ (for example, $d=1,2,3$ ) the integrals, which are the coefficients of the final linear system, can be evaluated analytically; for greater values of $d$, 
TABLE 6. Minimum and maximum value of $\left|u_{128}^{\star}(y)-u_{N}(y)\right|$ with $y \in\{0.1,0.2, \ldots, 0.9\}$ obtained by the product-integration method on graded meshes applied to $(2.1)$ with $f(y)=y$.

\begin{tabular}{|c|c|c|c|c|c|}
\hline & $d=1$ & $d=2$ & $d=3$ & $d=4$ & $d=5$ \\
& $q=2.1$ & $q=2.6$ & $q=3.1$ & $q=3.6$ & $q=4.1$ \\
\hline$N=4$ & $1.9 \mathrm{E}-04$ & $2.0 \mathrm{E}-04$ & $5.1 \mathrm{E}-06$ & $3.0 \mathrm{E}-06$ & $5.2 \mathrm{E}-06$ \\
& $6.0 \mathrm{E}-03$ & $1.0 \mathrm{E}-03$ & $8.8 \mathrm{E}-05$ & $4.7 \mathrm{E}-05$ & $2.4 \mathrm{E}-05$ \\
\hline$C N$ & $3.1 \mathrm{E}+00$ & $3.6 \mathrm{E}+00$ & $4.4 \mathrm{E}+00$ & $4.9 \mathrm{E}+00$ & $5.3 \mathrm{E}+00$ \\
\hline$N=8$ & $1.9 \mathrm{E}-04$ & $4.3 \mathrm{E}-06$ & $2.4 \mathrm{E}-07$ & $6.0 \mathrm{E}-08$ & $1.0 \mathrm{E}-08$ \\
& $6.4 \mathrm{E}-04$ & $1.4 \mathrm{E}-04$ & $3.0 \mathrm{E}-06$ & $1.2 \mathrm{E}-06$ & $4.3 \mathrm{E}-07$ \\
\hline$C N$ & $3.4 \mathrm{E}+00$ & $4.0 \mathrm{E}+00$ & $5.0 \mathrm{E}+00$ & $5.7 \mathrm{E}+00$ & $6.4 \mathrm{E}+00$ \\
\hline$N=16$ & $4.0 \mathrm{E}-06$ & $7.3 \mathrm{E}-07$ & $9.2 \mathrm{E}-09$ & $8.8 \mathrm{E}-09$ & $2.4 \mathrm{E}-08$ \\
& $5.6 \mathrm{E}-05$ & $1.4 \mathrm{E}-05$ & $8.5 \mathrm{E}-08$ & $1.2 \mathrm{E}-08$ & $1.3 \mathrm{E}-06$ \\
\hline$C N$ & $3.7 \mathrm{E}+00$ & $4.6 \mathrm{E}+00$ & $5.3 \mathrm{E}+00$ & $5.9 \mathrm{E}+00$ & $7.0 \mathrm{E}+04$ \\
\hline$N=32$ & $3.6 \mathrm{E}-07$ & $2.9 \mathrm{E}-08$ & $1.3 \mathrm{E}-09$ & $9.1 \mathrm{E}-09$ & $2.9 \mathrm{E}-08$ \\
& $1.2 \mathrm{E}-05$ & $9.5 \mathrm{E}-07$ & $4.0 \mathrm{E}-09$ & $6.3 \mathrm{E}-07$ & $1.5 \mathrm{E}-06$ \\
\hline$C N$ & $3.9 \mathrm{E}+00$ & $4.8 \mathrm{E}+00$ & $5.3 \mathrm{E}+00$ & $2.7 \mathrm{E}+04$ & $3.1 \mathrm{E}+12$ \\
\hline$N=64$ & $1.3 \mathrm{E}-08$ & $5.6 \mathrm{E}-10$ & $1.6 \mathrm{E}-11$ & $2.9 \mathrm{E}-10$ & $2.6 \mathrm{E}-02$ \\
& $2.0 \mathrm{E}-06$ & $6.6 \mathrm{E}-08$ & $1.2 \mathrm{E}-09$ & $2.0 \mathrm{E}-07$ & $1.5 \mathrm{E}+00$ \\
\hline$C N$ & $4.0 \mathrm{E}+00$ & $5.0 \mathrm{E}+00$ & $5.4 \mathrm{E}+00$ & $1.5 \mathrm{E}+09$ & $2.6 \mathrm{E}+19$ \\
\hline
\end{tabular}

this type of approach is quite cumbersome. Moreover, a numerical approach based on quadrature rules, of Gaussian type when the $s$-variable is sufficiently far from $[-1,1]$ and of product type otherwise, is equally onerous.

In Tables 6 and 7, we report the minimum and the maximum absolute errors generated by the approximant $u_{N}(y)$, taking as reference value the corresponding approximant $u_{128}^{\star}(y)$, obtained with $N=128$ and $d=3$.

By examining the rates of convergence shown in Tables 2, 3 and 4 we notice that they appear superior to those proved in Theorem 1. A possible explanation could be the following one.

Since for each chosen value of $n$ we collocate the integral equation at the $n$ distinct points $\left\{t_{n j}\right\}$, the zeros of the Legendre polynomial of degree $n$, and the fixed-point singularities of $\delta_{0}^{\star}(t, s)$ in our cases never coincide with one of the above zeros, the function $\delta_{0}^{\star}\left(t, t_{n j}\right)$ is actually analytic with respect to the $t$-variable. For completeness, we have tested also the particular case for which the singularity $t=s=0$ of $\delta_{0}^{\star}(t, s)$ when $f(y)=|y|$ coincides with one of the zeros of the Legendre polynomials. For this, we have chosen odd values of $n$. This has not made the numerical results worse. Therefore, it seems that the presence of the $\delta_{0}^{\star}(t, s)$ does not have any effect on the quadrature error, and that this latter could be estimated on the ground of the asymptotic expansion of $\varphi$, using the bounds of Lemma 3. If this is true, we have that the expected accuracy improvement should be of order $O\left(n^{-4 \alpha_{0}+\varepsilon}\right)$ when $f(y)=y, O\left(n^{-4 \alpha_{0}+\varepsilon}+n^{-2 \alpha_{1}+1+\varepsilon}\right)$ when $f(y)=|y|$ and $O\left(n^{-4 \alpha_{0}+\varepsilon}+n^{-\alpha_{1}+1+\varepsilon}\right)$ when $f(y)=\operatorname{sgn}(y)$. Taking into account these orders of convergence, it appears that the parameters $\left\{\alpha_{k}\right\}$ can be chosen smaller than those suggested in Theorem 1 or Remark 2 . We can obtain $O\left(n^{-l-1+\varepsilon}\right)$, by choosing $\alpha_{0}=\alpha_{1}=\left\lceil\frac{l+1}{4}\right\rceil$ when $f(y)=y, \alpha_{0}=\alpha_{2}=\left\lceil\frac{\alpha_{1}-1}{4}\right\rceil$ with $\alpha_{1}=\left\lceil\frac{l+2}{2}\right\rceil$ when $f(y)=|y|$, or $\alpha_{1}=l+2$ when $f(y)=\operatorname{sgn}(y)$. To check, for example, the validity of 
TABLE 7. Minimum and maximum value of $\left|u_{128}^{\star}(y)-u_{N}(y)\right|$ with $y \in\{0.1,0.2, \ldots, 0.9\}$ obtained by the Galerkin method on graded meshes applied to $(2.1)$ with $f(y)=y$.

\begin{tabular}{|c|c|c|c|c|c|}
\hline & $d=1$ & $d=2$ & $d=3$ & $d=4$ & $d=5$ \\
& $q=2.1$ & $q=2.6$ & $q=3.1$ & $q=3.6$ & $q=4.1$ \\
\hline$N=4$ & $7.8 \mathrm{E}-03$ & $1.1 \mathrm{E}-03$ & $1.6 \mathrm{E}-04$ & $7.0 \mathrm{E}-05$ & $4.6 \mathrm{E}-05$ \\
& $4.1 \mathrm{E}-02$ & $1.2 \mathrm{E}-02$ & $1.1 \mathrm{E}-03$ & $9.9 \mathrm{E}-04$ & $4.6 \mathrm{E}-04$ \\
\hline$C N$ & $7.4 \mathrm{E}+00$ & $1.0 \mathrm{E}+01$ & $1.4 \mathrm{E}+01$ & $2.1 \mathrm{E}+01$ & $3.1 \mathrm{E}+01$ \\
\hline$N=8$ & $4.2 \mathrm{E}-03$ & $9.4 \mathrm{E}-05$ & $4.1 \mathrm{E}-06$ & $2.4 \mathrm{E}-06$ & $3.3 \mathrm{E}-06$ \\
& $1.1 \mathrm{E}-01$ & $2.2 \mathrm{E}-03$ & $1.3 \mathrm{E}-04$ & $2.0 \mathrm{E}-05$ & $6.7 \mathrm{E}-06$ \\
\hline$C N$ & $1.9 \mathrm{E}+01$ & $4.0 \mathrm{E}+01$ & $8.8 \mathrm{E}+01$ & $2.0 \mathrm{E}+02$ & $4.2 \mathrm{E}+02$ \\
\hline$N=16$ & $1.3 \mathrm{E}-04$ & $9.4 \mathrm{E}-06$ & $8.0 \mathrm{E}-07$ & $8.3 \mathrm{E}-08$ & $3.1 \mathrm{E}-09$ \\
& $2.6 \mathrm{E}-03$ & $3.5 \mathrm{E}-04$ & $8.4 \mathrm{E}-06$ & $1.3 \mathrm{E}-06$ & $9.4 \mathrm{E}-07$ \\
\hline$C N$ & $5.6 \mathrm{E}+01$ & $1.9 \mathrm{E}+02$ & $6.3 \mathrm{E}+02$ & $3.0 \mathrm{E}+03$ & $1.3 \mathrm{E}+07$ \\
\hline$N=32$ & $3.5 \mathrm{E}-05$ & $5.9 \mathrm{E}-06$ & $6.4 \mathrm{E}-08$ & $4.1 \mathrm{E}-08$ & $1.4 \mathrm{E}-09$ \\
& $1.2 \mathrm{E}-03$ & $4.5 \mathrm{E}-05$ & $4.9 \mathrm{E}-07$ & $1.2 \mathrm{E}-06$ & $1.9 \mathrm{E}-07$ \\
\hline$C N$ & $1.8 \mathrm{E}+02$ & $9.9 \mathrm{E}+02$ & $4.7 \mathrm{E}+03$ & $2.8 \mathrm{E}+07$ & $2.1 \mathrm{E}+15$ \\
\hline$N=64$ & $1.5 \mathrm{E}-05$ & $2.7 \mathrm{E}-07$ & $1.3 \mathrm{E}-10$ & $5.7 \mathrm{E}-10$ & $1.0 \mathrm{E}-09$ \\
& $2.6 \mathrm{E}-04$ & $6.4 \mathrm{E}-06$ & $4.1 \mathrm{E}-08$ & $3.7 \mathrm{E}-08$ & $1.5 \mathrm{E}-07$ \\
\hline$C N$ & $6.5 \mathrm{E}+02$ & $5.5 \mathrm{E}+03$ & $1.2 \mathrm{E}+05$ & $3.7 \mathrm{E}+12$ & $2.5 \mathrm{E}+22$ \\
\hline
\end{tabular}

TABLE 8. Minimum and maximum value of $\left|u_{128}(y)-u_{n}(y)\right|$ with $y \in\{0.1,0.2, \ldots, 0.9\}$ obtained by the product-integration method $\left(\alpha_{0} \equiv \alpha_{1}=2\right)$ applied to $(2.9)$ when $f(y)=y$.

\begin{tabular}{|c|c|c|c|c|c|}
\hline & $n=4$ & $n=8$ & $n=16$ & $n=32$ & $n=64$ \\
\hline min & $5.3 \mathrm{E}-03$ & $1.5 \mathrm{E}-05$ & $1.2 \mathrm{E}-09$ & $6.0 \mathrm{E}-12$ & $5.5 \mathrm{E}-14$ \\
\hline max & $8.5 \mathrm{E}-02$ & $2.3 \mathrm{E}-04$ & $4.6 \mathrm{E}-08$ & $1.5 \mathrm{E}-10$ & $4.5 \mathrm{E}-13$ \\
\hline$C N$ & $2.2 \mathrm{E}+00$ & $2.2 \mathrm{E}+00$ & $2.5 \mathrm{E}+00$ & $2.8 \mathrm{E}+00$ & $3.0 \mathrm{E}+00$ \\
\hline
\end{tabular}

the latter bound, we have once more applied our product-integration to equation (2.9), but this time choosing $\alpha_{0}=\alpha_{2}=3$ and $\alpha_{1}=13$. In Table 9 , we give some of the corresponding absolute errors we have obtained, while in Table 10, we report the relative errors corresponding to the original solution $u$.

By comparing Table 9 with Table 4, we notice indeed an improvement of the accuracy which was not predicted by Theorem 1 .

We have extensively tested also the collocation method described in Section 4.

Product-integration appears superior from all points of view. In Table 11 we give a sample of the results we have obtained (compare them with the corresponding values in Table 2 ).

Results very similar to those reported in the tables and concerning equation (2.1) were obtained also for equations of the type (2.12), with $h_{2}$ and $h_{3}$ assuming the same values defined at the beginning of Section 5. In Tables 12 and 13, we give the results of two of our experiments.

All computations have been performed on a PC computer using 16-digit double precision arithmetic. 
TABLE 9. Values of $\left|\varphi_{256}(s)-\varphi_{n}(s)\right|$ obtained by the productintegration method $\left(\alpha_{0} \equiv \alpha_{2}=3, \alpha_{1}=13\right)$ applied to (2.9) when $f(y)=\operatorname{sgn}(y)$.

\begin{tabular}{|c|c|c|c|c|c|c|c|}
\hline$s$ & $\varphi_{256}(s)$ & $n=4$ & $n=8$ & $n=16$ & $n=32$ & $n=64$ & $n=128$ \\
\hline 0.1 & $1.105650000174631 \mathrm{E}-09$ & $6.1 \mathrm{E}-12$ & $3.0 \mathrm{E}-12$ & $1.5 \mathrm{E}-13$ & $6.1 \mathrm{E}-16$ & $1.5 \mathrm{E}-23$ & $2.3 \mathrm{E}-23$ \\
\hline 0.2 & $3.578268188275185 \mathrm{E}-06$ & $1.5 \mathrm{E}-07$ & $6.4 \mathrm{E}-08$ & $1.3 \mathrm{E}-09$ & $1.4 \mathrm{E}-12$ & $6.0 \mathrm{E}-16$ & $4.1 \mathrm{E}-19$ \\
\hline 0.3 & $3.554836861728969 \mathrm{E}-04$ & $4.8 \mathrm{E}-05$ & $1.4 \mathrm{E}-05$ & $9.1 \mathrm{E}-08$ & $2.3 \mathrm{E}-10$ & $1.5 \mathrm{E}-13$ & $2.0 \mathrm{E}-18$ \\
\hline 0.4 & $8.261042908237580 \mathrm{E}-03$ & $2.4 \mathrm{E}-03$ & $3.6 \mathrm{E}-04$ & $4.9 \mathrm{E}-06$ & $1.4 \mathrm{E}-09$ & $1.1 \mathrm{E}-12$ & $1.0 \mathrm{E}-16$ \\
\hline 0.5 & $8.504343096280330 \mathrm{E}-02$ & $4.1 \mathrm{E}-02$ & $5.9 \mathrm{E}-04$ & $3.6 \mathrm{E}-05$ & $3.9 \mathrm{E}-08$ & $1.1 \mathrm{E}-12$ & $1.2 \mathrm{E}-15$ \\
\hline 0.6 & $5.313939231004428 \mathrm{E}-01$ & $3.4 \mathrm{E}-01$ & $4.7 \mathrm{E}-02$ & $1.7 \mathrm{E}-04$ & $3.5 \mathrm{E}-08$ & $3.5 \mathrm{E}-12$ & $7.4 \mathrm{E}-15$ \\
0.7 & $2.411843395766954 \mathrm{E}+00$ & $1.6 \mathrm{E}+00$ & $2.1 \mathrm{E}-01$ & $1.6 \mathrm{E}-03$ & $1.3 \mathrm{E}-06$ & $2.2 \mathrm{E}-11$ & $3.3 \mathrm{E}-14$ \\
0.8 & $7.248557773538451 \mathrm{E}+00$ & $4.9 \mathrm{E}+00$ & $1.5 \mathrm{E}-01$ & $1.8 \mathrm{E}-02$ & $5.7 \mathrm{E}-06$ & $6.3 \mathrm{E}-11$ & $6.2 \mathrm{E}-14$ \\
\hline 0.9 & $8.182595978508354 \mathrm{E}+00$ & $8.5 \mathrm{E}+00$ & $6.3 \mathrm{E}-01$ & $3.1 \mathrm{E}-02$ & $6.8 \mathrm{E}-06$ & $1.1 \mathrm{E}-10$ & $9.8 \mathrm{E}-14$ \\
\hline$C N$ & & $5.7 \mathrm{E}+00$ & $6.3 \mathrm{E}+00$ & $5.1 \mathrm{E}+00$ & $5.9 \mathrm{E}+00$ & $5.9 \mathrm{E}+00$ & $6.0 \mathrm{E}+00$ \\
\hline
\end{tabular}

TABLE 10. Values of $\left|u_{256}(y)-u_{n}(y)\right| /\left|u_{256}(y)\right|$ obtained by the product-integration method $\left(\alpha_{0} \equiv \alpha_{2}=3, \alpha_{1}=13\right)$ applied to (2.9) when $f(y)=\operatorname{sgn}(y)$.

\begin{tabular}{|c|c|c|c|c|c|c|c|}
\hline$y$ & $u_{256}(y)$ & $n=4$ & $n=8$ & $n=16$ & $n=32$ & $n=64$ & $n=128$ \\
\hline 0.1 & $1.346827834095726 \mathrm{E}+00$ & $6.6 \mathrm{E}-01$ & $9.7 \mathrm{E}-02$ & $7.3 \mathrm{E}-03$ & $4.6 \mathrm{E}-07$ & $1.6 \mathrm{E}-12$ & $1.2 \mathrm{E}-14$ \\
\hline 0.2 & $1.591034079407878 \mathrm{E}+00$ & $6.5 \mathrm{E}-01$ & $5.4 \mathrm{E}-02$ & $1.4 \mathrm{E}-04$ & $4.7 \mathrm{E}-07$ & $8.7 \mathrm{E}-12$ & $1.8 \mathrm{E}-14$ \\
\hline 0.3 & $1.784057700440473 \mathrm{E}+00$ & $6.6 \mathrm{E}-01$ & $1.2 \mathrm{E}-02$ & $1.6 \mathrm{E}-03$ & $1.1 \mathrm{E}-06$ & $8.7 \mathrm{E}-12$ & $1.5 \mathrm{E}-14$ \\
\hline 0.4 & $1.934456814569050 \mathrm{E}+00$ & $6.8 \mathrm{E}-01$ & $2.1 \mathrm{E}-02$ & $2.5 \mathrm{E}-03$ & $8.3 \mathrm{E}-07$ & $8.6 \mathrm{E}-12$ & $8.7 \mathrm{E}-15$ \\
\hline 0.5 & $2.044820625860425 \mathrm{E}+00$ & $7.2 \mathrm{E}-01$ & $4.6 \mathrm{E}-02$ & $2.3 \mathrm{E}-03$ & $1.9 \mathrm{E}-06$ & $9.8 \mathrm{E}-12$ & $1.8 \mathrm{E}-14$ \\
\hline 0.6 & $2.115382947820011 \mathrm{E}+00$ & $7.8 \mathrm{E}-01$ & $6.3 \mathrm{E}-02$ & $9.3 \mathrm{E}-04$ & $2.0 \mathrm{E}-07$ & $8.4 \mathrm{E}-12$ & $1.8 \mathrm{E}-14$ \\
\hline 0.7 & $2.144773614089209 \mathrm{E}+00$ & $8.8 \mathrm{E}-01$ & $7.3 \mathrm{E}-02$ & $1.3 \mathrm{E}-03$ & $2.5 \mathrm{E}-06$ & $8.7 \mathrm{E}-12$ & $2.8 \mathrm{E}-14$ \\
\hline 0.8 & $2.129502891667054 \mathrm{E}+00$ & $1.0 \mathrm{E}+00$ & $7.6 \mathrm{E}-02$ & $3.5 \mathrm{E}-03$ & $1.7 \mathrm{E}-08$ & $1.0 \mathrm{E}-11$ & $1.0 \mathrm{E}-14$ \\
\hline 0.9 & $2.060852898381479 \mathrm{E}+00$ & $1.2 \mathrm{E}+00$ & $7.5 \mathrm{E}-02$ & $3.4 \mathrm{E}-03$ & $2.4 \mathrm{E}-06$ & $1.3 \mathrm{E}-11$ & $1.4 \mathrm{E}-14$ \\
\hline$C N$ & & $5.7 \mathrm{E}+00$ & $6.3 \mathrm{E}+00$ & $5.1 \mathrm{E}+00$ & $5.9 \mathrm{E}+00$ & $5.9 \mathrm{E}+00$ & $6.0 \mathrm{E}+00$ \\
\hline
\end{tabular}

TABLE 11. Values of $\left|\varphi_{128}(s)-\varphi_{n}(s)\right|$ obtained by the collocation method $\left(\alpha_{0} \equiv \alpha_{1}=3\right)$ applied to $(2.9)$ when $f(y)=y$.

\begin{tabular}{|c|c|c|c|c|c|c|}
\hline$s$ & $\varphi_{128}(s)$ & $n=4$ & $n=8$ & $n=16$ & $n=32$ & $n=64$ \\
\hline 0.1 & $7.990433124158405 \mathrm{E}-01$ & $8.0 \mathrm{E}-02$ & $3.7 \mathrm{E}-03$ & $7.7 \mathrm{E}-07$ & $6.6 \mathrm{E}-12$ & $2.4 \mathrm{E}-15$ \\
\hline 0.2 & $1.432816553358987 \mathrm{E}+00$ & $5.2 \mathrm{E}-02$ & $5.8 \mathrm{E}-03$ & $9.3 \mathrm{E}-06$ & $1.3 \mathrm{E}-11$ & $2.9 \mathrm{E}-15$ \\
\hline 0.3 & $1.788544031476075 \mathrm{E}+00$ & $1.4 \mathrm{E}-01$ & $2.5 \mathrm{E}-02$ & $4.6 \mathrm{E}-06$ & $2.0 \mathrm{E}-11$ & $8.0 \mathrm{E}-15$ \\
\hline 0.4 & $1.834976166101300 \mathrm{E}+00$ & $4.7 \mathrm{E}-01$ & $3.2 \mathrm{E}-02$ & $1.6 \mathrm{E}-05$ & $2.2 \mathrm{E}-11$ & $4.4 \mathrm{E}-15$ \\
\hline 0.5 & $1.618600621724187 \mathrm{E}+00$ & $8.4 \mathrm{E}-01$ & $1.0 \mathrm{E}-02$ & $1.6 \mathrm{E}-05$ & $1.2 \mathrm{E}-11$ & $3.6 \mathrm{E}-15$ \\
\hline 0.6 & $1.235223000322232 \mathrm{E}+00$ & $1.1 \mathrm{E}+00$ & $3.1 \mathrm{E}-02$ & $9.3 \mathrm{E}-06$ & $3.1 \mathrm{E}-11$ & $9.6 \mathrm{E}-15$ \\
\hline 0.7 & $7.946035861030149 \mathrm{E}-01$ & $1.1 \mathrm{E}+00$ & $4.7 \mathrm{E}-02$ & $2.9 \mathrm{E}-05$ & $9.5 \mathrm{E}-11$ & $1.8 \mathrm{E}-14$ \\
\hline 0.8 & $3.940370457228314 \mathrm{E}-01$ & $5.8 \mathrm{E}-01$ & $2.7 \mathrm{E}-03$ & $3.1 \mathrm{E}-05$ & $4.5 \mathrm{E}-11$ & $3.2 \mathrm{E}-14$ \\
\hline 0.9 & $1.088041738424818 \mathrm{E}-01$ & $4.6 \mathrm{E}-01$ & $6.6 \mathrm{E}-02$ & $3.8 \mathrm{E}-05$ & $8.3 \mathrm{E}-11$ & $7.4 \mathrm{E}-14$ \\
\hline$C N$ & & $9.3 \mathrm{E}+00$ & $2.0 \mathrm{E}+01$ & $2.2 \mathrm{E}+01$ & $4.4 \mathrm{E}+01$ & $7.9 \mathrm{E}+01$ \\
\hline
\end{tabular}


TABLE 12. Values of $\left|\varphi_{256}(s)-\varphi_{n}(s)\right|$ obtained by the productintegration method $\left(\alpha_{0} \equiv \alpha_{2}=4, \alpha_{1}=9\right)$ applied to (2.14) when $\alpha=-0.25$ and $f(y)=|y|$.

\begin{tabular}{|c|c|c|c|c|c|c|c|}
\hline$s$ & $\varphi_{256}(s)$ & $n=4$ & $n=8$ & $n=16$ & $n=32$ & $n=64$ & $n=128$ \\
\hline 0.1 & $-2.624209448527758 \mathrm{E}-06$ & $7.3 \mathrm{E}-08$ & $1.4 \mathrm{E}-07$ & $6.7 \mathrm{E}-09$ & $1.2 \mathrm{E}-12$ & $1.9 \mathrm{E}-13$ & $4.5 \mathrm{E}-15$ \\
\hline 0.2 & $-4.716640031503962 \mathrm{E}-04$ & $6.2 \mathrm{E}-06$ & $7.2 \mathrm{E}-06$ & $1.5 \mathrm{E}-06$ & $2.3 \mathrm{E}-09$ & $5.3 \mathrm{E}-11$ & $1.3 \mathrm{E}-13$ \\
\hline 0.3 & $-8.025815474622011 \mathrm{E}-03$ & $6.7 \mathrm{E}-04$ & $6.3 \mathrm{E}-04$ & $8.6 \mathrm{E}-06$ & $5.2 \mathrm{E}-08$ & $2.8 \mathrm{E}-10$ & $9.0 \mathrm{E}-16$ \\
\hline 0.4 & $-4.674063163625496 \mathrm{E}-02$ & $8.9 \mathrm{E}-03$ & $4.4 \mathrm{E}-03$ & $1.2 \mathrm{E}-04$ & $1.2 \mathrm{E}-07$ & $1.6 \mathrm{E}-11$ & $2.2 \mathrm{E}-15$ \\
\hline 0.5 & $-1.078622543304390 \mathrm{E}-01$ & $4.3 \mathrm{E}-02$ & $4.4 \mathrm{E}-03$ & $3.2 \mathrm{E}-04$ & $8.4 \mathrm{E}-08$ & $6.8 \mathrm{E}-11$ & $1.4 \mathrm{E}-15$ \\
\hline 0.6 & $6.075508133810709 \mathrm{E}-02$ & $9.6 \mathrm{E}-02$ & $1.9 \mathrm{E}-02$ & $4.1 \mathrm{E}-04$ & $1.8 \mathrm{E}-07$ & $9.8 \mathrm{E}-12$ & $3.6 \mathrm{E}-14$ \\
\hline 0.7 & $8.277693624489910 \mathrm{E}-01$ & $9.6 \mathrm{E}-02$ & $3.3 \mathrm{E}-02$ & $1.2 \mathrm{E}-03$ & $1.4 \mathrm{E}-08$ & $8.8 \mathrm{E}-12$ & $6.6 \mathrm{E}-15$ \\
\hline 0.8 & $1.457126961511843 \mathrm{E}+00$ & $7.6 \mathrm{E}-02$ & $2.8 \mathrm{E}-02$ & $6.3 \mathrm{E}-04$ & $1.4 \mathrm{E}-08$ & $2.0 \mathrm{E}-12$ & $6.7 \mathrm{E}-16$ \\
\hline 0.9 & $6.289732059402273 \mathrm{E}-01$ & $6.3 \mathrm{E}-02$ & $1.5 \mathrm{E}-02$ & $1.3 \mathrm{E}-04$ & $3.3 \mathrm{E}-08$ & $7.1 \mathrm{E}-13$ & $1.4 \mathrm{E}-15$ \\
\hline$C N$ & & $1.5 \mathrm{E}+00$ & $1.9 \mathrm{E}+00$ & $2.0 \mathrm{E}+00$ & $2.1 \mathrm{E}+00$ & $2.1 \mathrm{E}+00$ & $2.1 \mathrm{E}+00$ \\
\hline
\end{tabular}

TABLE 13. Values of $\left|\varphi_{256}(s)-\varphi_{n}(s)\right|$ obtained by the productintegration method $\left(\alpha_{0} \equiv \alpha_{2}=4, \alpha_{1}=9\right)$ applied to (2.14) when $\alpha=-0.5$ and $f(y)=|y|$.

\begin{tabular}{|c|c|c|c|c|c|c|c|}
\hline$s \varphi_{256}(s)$ & $n=4$ & $n=8$ & $n=16$ & $n=32$ & $n=64$ & $n=128$ & \\
\hline 0.1 & $-2.03075320455921 \mathrm{E}-06$ & $1.7 \mathrm{E}-06$ & $5.0 \mathrm{E}-07$ & $2.3 \mathrm{E}-10$ & $2.8 \mathrm{E}-10$ & $5.8 \mathrm{E}-11$ & $2.5 \mathrm{E}-12$ \\
\hline 0.2 & $-3.649633695579144 \mathrm{E}-04$ & $2.3 \mathrm{E}-04$ & $1.6 \mathrm{E}-05$ & $3.0 \mathrm{E}-06$ & $1.8 \mathrm{E}-07$ & $6.6 \mathrm{E}-09$ & $1.8 \mathrm{E}-11$ \\
\hline 0.3 & $-6.195981003468890 \mathrm{E}-03$ & $1.5 \mathrm{E}-03$ & $2.0 \mathrm{E}-03$ & $8.7 \mathrm{E}-06$ & $2.0 \mathrm{E}-06$ & $1.5 \mathrm{E}-08$ & $3.0 \mathrm{E}-13$ \\
\hline 0.4 & $-3.552048755285684 \mathrm{E}-02$ & $8.0 \mathrm{E}-03$ & $1.5 \mathrm{E}-02$ & $6.2 \mathrm{E}-05$ & $4.2 \mathrm{E}-06$ & $2.3 \mathrm{E}-11$ & $8.4 \mathrm{E}-14$ \\
\hline 0.5 & $-7.661082843144207 \mathrm{E}-02$ & $6.4 \mathrm{E}-02$ & $1.7 \mathrm{E}-02$ & $2.6 \mathrm{E}-04$ & $8.6 \mathrm{E}-07$ & $2.3 \mathrm{E}-09$ & $4.7 \mathrm{E}-14$ \\
\hline 0.6 & $7.159355852844762 \mathrm{E}-02$ & $1.3 \mathrm{E}-01$ & $4.2 \mathrm{E}-02$ & $7.3 \mathrm{E}-04$ & $3.6 \mathrm{E}-06$ & $3.9 \mathrm{E}-10$ & $5.2 \mathrm{E}-14$ \\
\hline 0.7 & $6.800014252004067 \mathrm{E}-01$ & $4.5 \mathrm{E}-02$ & $6.4 \mathrm{E}-02$ & $3.3 \mathrm{E}-03$ & $1.1 \mathrm{E}-06$ & $1.1 \mathrm{E}-10$ & $5.0 \mathrm{E}-14$ \\
\hline 0.8 & $1.184139315302078 \mathrm{E}+00$ & $1.2 \mathrm{E}-02$ & $2.5 \mathrm{E}-02$ & $2.8 \mathrm{E}-03$ & $2.6 \mathrm{E}-07$ & $2.0 \mathrm{E}-11$ & $3.8 \mathrm{E}-15$ \\
\hline 0.9 & $5.380551334237226 \mathrm{E}-01$ & $1.1 \mathrm{E}-01$ & $1.7 \mathrm{E}-02$ & $8.1 \mathrm{E}-04$ & $7.5 \mathrm{E}-07$ & $5.6 \mathrm{E}-12$ & $2.7 \mathrm{E}-14$ \\
\hline$C N$ & & $1.8 \mathrm{E}+00$ & $2.1 \mathrm{E}+00$ & $2.0 \mathrm{E}+00$ & $2.3 \mathrm{E}+00$ & $2.4 \mathrm{E}+00$ & $2.4 \mathrm{E}+00$ \\
\hline
\end{tabular}

\section{REFERENCES}

[1] K. E. Atkinson, A survey of numerical methods for the solution of Fredholm integral equations of the second kind, SIAM, Philadelphia, 1976. MR 58:3577

[2] G. Criscuolo, G. Mastroianni, G. Monegato, Convergence properties of a class of product formulas for weakly singular integral equations, Math. Comp. 55 (1990), 213-230. MR 90m:65230

[3] D. Elliott, S. Prössdorf, An algorithm for the approximate solution of integral equations of Mellin type, Numer. Math. 70 (1995), 427-452. MR 96d:65206

[4] J. Elschner, I. G. Graham, An optimal order collocation method for first kind boundary integral equations on polygons, Numer. Math. 70 (1995), 1-31. MR 95m:65215

[5] I. G. Graham, Galerkin methods for second kind integral equations with singularities, Math. Comp. 39 (1982), 519-533. MR 84d:65090

[6] I. G. Graham, Singularity expansions for the solutions of second kind Fredholm integral equations with weakly singular convolution kernels, J. Integral Equations 4 (1982), 1-30. MR 83e: 45006

[7] K. Jörgens, Linear Integral Operators, Pitman London, 1982. MR 83j:45001

[8] R. Kress, A Nyström method for boundary integral equations in domains with corners, Numer. Math. 58 (1990), 145-161. MR 91m:65239

[9] G. G. Lorentz, Approximation of Functions, Holt, Rinehart and Winston, New York, 1966. MR 35:4642

[10] G. Mastroianni, S. Prössdorf, A quadrature method for Cauchy integral equations with weakly singular perturbation kernel, J. Integral Equations Appl. 4 (1992), 205-228. MR 93g:45013 
[11] G. Mastroianni, M. G. Russo, Lagrange interpolation in weighted Besov spaces, to appear in Constr. Approx.

[12] S. G. Mikhlin, S. Prössdorf, Singular Integral Operators, Springer-Verlag, Berlin 1986. MR 88e: 47097

[13] G. Monegato, Product integration for one-dimensional integral equations of Fredholm type, Atti Sem. Mat. Fis. Univ. Modena 40 (1992), 653-666. MR 93j:45012

[14] G. Monegato, V. Colombo, Product integration for the linear transport equation in slab geometry, Numer. Math. 52 (1988), 219-240; Errata, ibid. 53 (1988), 739. MR 88k:65133; MR 89g:65139

[15] G. Monegato, I. H. Sloan, Numerical solution of the generalized airfoil equation for an airfoil with a flap, SIAM J. Numer. Anal. 34 (1997), 2288-2305. CMP 98:04

[16] P. Nevai, Mean convergence of Lagrange interpolation.III, Trans. Amer. Math. Soc. 282 (1984), 669-698. MR 85c:41009

[17] J. Pitkäranta, On the differential properties of solutions to Fredholm equations with weakly singular kernels, J. Inst. Math. Appl. 24 (1979), 109-119. MR 80c:65157

[18] S. Prössdorf, B. Silbermann, Numerical Analysis for Integral and Related Operator Equations, Akademie-Verlag, Berlin, and Birkhäuser-Verlag, Basel, 1991. MR 94f:65126a; MR 94f: $65126 \mathrm{~b}$

[19] G. R. Richter, On weakly singular Fredholm integral equations with displacement kernels, J. Math. Anal. Appl. 55 (1976), 32-42. MR 53:11322

[20] C. Schneider, Regularity of the solution to a class of weakly singular Fredholm integral equations of the second kind, Integral Equations Operator Theory 2 (1979), 62-68. MR 80f:45002

[21] C. Schneider, Product integration for weakly singular integral equations, Math. Comp. 36 (1981), 207-213. MR 82c:65090

[22] I. H. Sloan, Analysis of general quadrature methods for integral equations of the second kind, Numer. Math. 38 (1981), 263-278. MR 82m:65128

[23] I. H. Sloan, W. E. Smith, Properties of interpolatory product integration rules, SIAM J. Numer. Anal. 19 (1982), 427-442. MR 83e:41032

[24] W. E. Smith, I. H. Sloan, Product-integration rules based on the zeros of orthogonal polynomials, SIAM J. Numer. Anal. 17 (1980), 1-13. MR 81i:65018

[25] G. Vainikko, A. Pedas, The properties of solutions of weakly singular integral equations, J. Austral. Math. Soc. Ser. B 22 (1981), 419-430. MR 82i:45014

[26] G. Vainikko, P. Uba, A piecewise polynomial approximation to the solution of an integral equation with weakly singular kernel, J. Austral. Math. Soc. Ser. B 22 (1981), 431-438. MR 82h:65100

[27] C. Abaci, The Scientific Desk Library Documentation System, Raleigh, North Carolina, 1994.

Dipartimento di Matematica, Politecnico di Torino, Corso Duca degli Abruzzi 24 , 10129 TORINO, ItALY

E-mail address: monegato@polito.it

E-mail address: scuderi@polito.it 